\title{
Cholecystokinin Facilitates Glutamate Release by Increasing the Number of Readily Releasable Vesicles and Releasing Probability
}

\author{
Pan-Yue Deng, ${ }^{1}$ Zhaoyang Xiao, ${ }^{1}$ Archana Jha, ${ }^{1}$ David Ramonet, ${ }^{1}$ Toshimitsu Matsui, ${ }^{2}$ Michael Leitges, ${ }^{3}$ Hee-Sup Shin, ${ }^{4}$ \\ James E. Porter, ${ }^{1}$ Jonathan D. Geiger, ${ }^{1}$ and Saobo Lei ${ }^{1}$ \\ ${ }^{1}$ Department of Pharmacology, Physiology and Therapeutics, School of Medicine and Health Sciences, University of North Dakota, Grand Forks, North \\ Dakota 58203, ${ }^{2}$ Hematology/Oncology, Department of Medicine, Kobe University Graduate School of Medicine, Chuo-ku, Kobe 650-1700, Japan, ${ }^{3}$ The \\ Biotechnology Centre of Oslo, University of Oslo, Blindern, N-0317, Oslo, Norway, and ${ }^{4}$ Center for Neural Science, Korea Institute of Science and \\ Technology, 136-791, Seoul, Republic of Korea
}

Cholecystokinin (CCK), a neuropeptide originally discovered in the gastrointestinal tract, is abundantly distributed in the mammalian brains including the hippocampus. Whereas CCK has been shown to increase glutamate concentration in the perfusate of hippocampal slices and in purified rat hippocampal synaptosomes, the cellular and molecular mechanisms whereby CCK modulates glutamatergic function remain unexplored. Here, we examined the effects of CCK on glutamatergic transmission in the hippocampus using whole-cell recordings from hippocampal slices. Application of CCK increased AMPA receptor-mediated EPSCs at perforant path-dentate gyrus granule cell, CA3-CA3 and Schaffer collateral-CA1 synapses without effects at mossy fiber-CA3 synapses. CCK-induced increases in AMPA EPSCs were mediated by CCK-2 receptors and were not modulated developmentally and transcriptionally. CCK reduced the coefficient of variation and paired-pulse ratio of AMPA EPSCs suggesting that CCK facilitates presynaptic glutamate release. CCK increased the release probability and the number of readily releasable vesicles with no effects on the rate of recovery from vesicle depletion. CCK-mediated increases in glutamate release required the functions of phospholipase $\mathrm{C}$, intracellular $\mathrm{Ca}^{2+}$ release and protein kinase $\mathrm{C} \gamma$. CCK released endogenously from hippocampal interneurons facilitated glutamatergic transmission. Our results provide a cellular and molecular mechanism to explain the roles of CCK in the brain.

\section{Introduction}

Cholecystokinin (CCK) interacts with two G-protein-coupled receptors: CCK-1 and CCK-2. Whereas CCK-1 receptors are present in peripheral tissues and in a few discrete brain regions including postrema, interpeduncular nucleus and nucleus tractus solitarius (Moran et al., 1986; Hill et al., 1987, 1990), CCK-2 receptors are the predominant form found in the brain (Van Dijk et al., 1984). Activation of CCK-1 and CCK-2 receptors increases the activity of phospholipase $\mathrm{C}$ (PLC) which in turn enhances the hydrolysis of phosphatidylinositol 4, 5-bisphosphate ( $\left.\mathrm{PIP}_{2}\right)$ into inositol trisphosphate $\left(\mathrm{IP}_{3}\right)$ to increase intracellular $\mathrm{Ca}^{2+}$ release, and diacylglycerol to activate protein kinase C (PKC) (Wank, 1995). Activation of CCK-1, but not CCK-2 receptors, also increases adenylyl cyclase activity which enhances the generation of cAMP and subsequent activation of protein kinase A (Wank, 1995).

Received Nov. 17, 2009; revised Feb. 21, 2010; accepted Feb. 27, 2010.

This work was supported by National Institutes of Health Grant R01MH082881 (S.L.).

Correspondence should be addressed to Saobo Lei, Department of Pharmacology, Physiology and Therapeutics, School of Medicine and Health Sciences, University of North Dakota, Grand Forks, ND 58203. E-mail: slei@medicine. nodak.edu.

P.-Y. Deng's present address: Department of Cell Biology and Physiology, Washington University in St. Louis School of Medicine, St. Louis, M0 63110.

D0I:10.1523/JNEUROSCI.5711-09.2010

Copyright $\odot 2010$ the authors $\quad 0270-6474 / 10 / 305136-13 \$ 15.00 / 0$
CCK is extensively expressed in the hippocampus. CCK-like immunoreactive perikarya are located in the dentate hilus and all layers of Ammon's horn (Greenwood et al., 1981). The CCKimmunoreactive neurons represent a subpopulation of GABAergic interneurons (Somogyi et al., 1984; Nunzi et al., 1985). CCKimmunoreactive fibers are located around the cell bodies in the stratum pyramidale of Ammon's horn and among the granule cells and especially the inner molecular layer of the dentate gyrus (Greenwood et al., 1981; Hefft and Jonas, 2005) suggesting that significant amounts of endogenous CCK are released in the hippocampus. The hippocampus also expresses a high density of CCK receptors. The dentate gyrus exhibits the highest numbers of binding sites for CCK and moderate labeling has been detected in the stratum pyramidale of CA3 and CA1 regions (Köhler and Chan-Palay, 1988; Kritzer et al., 1988) suggesting that CCK plays an important role in the hippocampus. Indeed, CCK has been shown to increase the excitabilities of dentate gyrus granule cells (Brooks and Kelly, 1985; Sinton, 1988), CA3 (Gronier and Debonnel, 1995) and CA1 (Dodd and Kelly, 1981; Jaffe et al., 1987; Boden and Hill, 1988; Böhme et al., 1988) pyramidal neurons and modulates GABAergic transmission in the hippocampus (Miller et al., 1997; Deng and Lei, 2006; Földy et al., 2007; Karson et al., 2008). In addition, CCK has been shown to increase glutamate release in the perfusate of hippocampal slices (Migaud et al., 1994) and from purified rat hippocampal synaptosomes 
(Breukel et al., 1997). However, the cellular and molecular mechanisms whereby CCK modulates glutamatergic synaptic transmission remain unexplored. In this study, we examined the effects of CCK on glutamatergic transmission in the hippocampus and our results demonstrate that CCK facilitates glutamate release in the hippocampus by increasing the number of readily releasable vesicles and releasing probability via PLC, intracellular $\mathrm{Ca}^{2+}$ and PKC signals. We also showed that endogenously released CCK from hippocampal interneurons facilitates glutamate release. CCK-mediated enhancement of glutamate release may be involved in CCK-induced facilitation of anxiety.

\section{Materials and Methods}

Slice preparation. Horizontal brain slices $(400 \mu \mathrm{m})$ including the hippocampus, subiculum and entorhinal cortex were cut using a vibrating blade microtome (VT1000S; Leica) from 15- to 22-d-old Sprague Dawley rats as described previously (Deng and Lei, 2006, 2007; Deng et al., 2009; Xiao et al., 2009). After being deeply anesthetized with isoflurane, rats were decapitated and their brains were dissected out in ice-cold saline solution that contained (in mM) $130 \mathrm{NaCl}, 24 \mathrm{NaHCO}_{3}, 3.5 \mathrm{KCl}, 1.25$ $\mathrm{NaH}_{2} \mathrm{PO}_{4}, 0.5 \mathrm{CaCl}_{2}, 5.0 \mathrm{MgCl}_{2}$ and 10 glucose, saturated with $95 \% \mathrm{O}_{2}$ and $5 \% \mathrm{CO}_{2}$, pH 7.4. Slices were initially incubated in the above solution at $35^{\circ} \mathrm{C}$ for $40 \mathrm{~min}$ for recovery and then kept at room temperature $\left(\sim 24^{\circ} \mathrm{C}\right)$ until use. All animal procedures conformed to the guidelines approved by the University of North Dakota Animal Care and Use Committee.

Recordings of synaptic currents. Whole-cell patch-clamp recordings using an Axopatch 200B or two Multiclamp 700B amplifiers in current- or voltage-clamp mode from in vitro hippocampal slices were used for experiments. Cells in the slices were visually identified with infrared video microscopy and differential interference contrast optics (Deng et al., 2006; Lei et al., 2007). Recording electrodes were filled with the solution containing (in mM) 100 Cs-gluconate, 0.6 EGTA, $5 \mathrm{MgCl}_{2}, 8 \mathrm{NaCl}, 2$ $\mathrm{ATP}_{2} \mathrm{Na}, 0.3 \mathrm{GTPNa}, 40$ HEPES and $1 \mathrm{QX}-314, \mathrm{pH}$ 7.3. The extracellular solution comprised (in mM) $130 \mathrm{NaCl}, 24 \mathrm{NaHCO}_{3}, 3.5 \mathrm{KCl}, 1.25$ $\mathrm{NaH}_{2} \mathrm{PO}_{4}, 2.5 \mathrm{CaCl}_{2}, 1.5 \mathrm{MgCl}_{2}$ and 10 glucose, saturated with $95 \% \mathrm{O}_{2}$ and $5 \% \mathrm{CO}_{2}, \mathrm{pH} 7.4$. Bicuculline $(10 \mu \mathrm{M})$ was included in the extracellular solution to block $\mathrm{GABA}_{\mathrm{A}}$ receptors. The holding potential was at $-60 \mathrm{mV}$. AMPA receptor-mediated EPSCs were evoked by placing a stimulation electrode in the middle to the inner one third of molecular layer of dentate gyrus to stimulate the medial perforant path or in the stratum radiatum of the $\mathrm{CA} 3$ region to stimulate the recurrent fibers or in the stratum radiatum of the CA1 region to stimulate the Schaffer collateral fibers in different experiments. Under these conditions, the recorded currents were completely blocked by application of DNQX $(10 \mu \mathrm{M})$ or GYKI $52466(100 \mu \mathrm{M})$ at the end of experiments confirming that they were mediated by AMPA receptors. Series resistance was rigorously monitored by the delivery of $5 \mathrm{mV}$ voltage steps after each evoked current. Experiments were discontinued if the series resistance changed by $>10 \%$. Miniature AMPA EPSCs (mEPSCs) were recorded from dentate gyrus granule cells in the presence of TTX $(0.5 \mu \mathrm{M})$. Data were filtered at $2 \mathrm{kHz}$, digitized at $10 \mathrm{kHz}$, acquired on-line and analyzed after-line using pCLAMP 9 software (Molecular Devices). The recorded mEPSCs were analyzed afterward using Mini Analysis 6.0.1 (Synaptosoft Inc.). To avoid potential desensitization induced by repeated bath applications of CCK, one slice was limited to only one application of CCK and only one cell was recorded from each slice.

Dual-electrode recordings and immunocytochemistry. The experiments examining the effects of endogenously released CCK on glutamate release (see Fig. 7) were conducted using a Multiclamp 700B amplifier. The stimulation electrode containing the extracellular solution was first placed into the internal molecular layer for stimulation of the perforant path. The patch electrode sealed to the interneuron contained (in $\mathrm{mM}$ ) 100 K-gluconate, 0.6 EGTA, $5 \mathrm{MgCl}_{2}, 8 \mathrm{NaCl}, 2 \mathrm{ATP}_{2} \mathrm{Na}, 0.3 \mathrm{GTPNa}, 40$ HEPES, pH 7.2-7.3. The patch electrode sealed to the granule cell contained the same Cs-gluconate solution described above. Both electrodes contained $0.2 \%$ biocytin. Data were collected only from the recordings of which the holding currents of the granule cells at $-60 \mathrm{mV}$ were less than
$-100 \mathrm{pA}$ and the resting membrane potentials of the interneurons were negative to $-60 \mathrm{mV}$. The extracellular solution contained bicuculline (10 $\mu \mathrm{M})$ to block $\mathrm{GABA}_{\mathrm{A}}$ receptors, CGP55845 $(5 \mu \mathrm{M})$ to block $\mathrm{GABA}_{\mathrm{B}}$ receptors, $\mathrm{AM} 251(10 \mu \mathrm{M})$ to block cannabinoid receptors and amastatin $(10 \mu \mathrm{M})$ to inhibit amino-peptidase (Su et al., 2002). After recordings, slices were fixed in $4 \%$ paraformaldehyde for $24 \mathrm{~h}$. After extensive washing in $0.1 \mathrm{M}$ PBS, slices were incubated with PBS containing 5\% normal donkey serum and $1 \%$ Triton $\mathrm{X}-100$ for $2 \mathrm{~h}$. Slices were then incubated with goat anti-CCK antibody (sc-21615, Santa Cruz Biotechnology, CA) at a dilution of $1: 100$ for $48 \mathrm{~h}$ at $4^{\circ} \mathrm{C}$. Slices were incubated with donkey anti-goat IgG-FITC (sc-2024, Santa Cruz Biotechnology, 1:200, for detecting CCK) and Texas red-conjugated streptavidin (SA-5006, Vector Laboratories, 1:200, for detecting biocytin-filled neurons) for $2 \mathrm{~h}$ at room temperature. After washing, slices were mounted on slides and coverslipped. Finally, slides were visualized with an Olympus Fluoview 300 confocal microscope and photographed. The specificity of the CCK immunoreactivity was confirmed by pretreatment of the CCK antibody with the corresponding CCK blocking peptide (1:5 by weight, sc-21615P, Santa Cruz Biotechnology Inc.) in PBS for $\sim 2 \mathrm{~h}$ at room temperature. The mixture was then diluted at 1:100 (according to the CCK primary antibody) and used for immunostaining with the same procedures described above.

Perforated patch-recordings of action potential $(A P)$ firing from dentate granule cells. Perforated-patch recordings were used to record AP firing from dentate granule cells as described previously (Deng and Lei, 2007). Recording pipettes were tip-filled with the above $\mathrm{K}^{+}$-gluconate intracellular solution and then back-filled with freshly prepared $\mathrm{K}^{+}$-gluconate intracellular solution containing amphotericin B $(200 \mu \mathrm{g} / \mathrm{ml}$, Calbiochem). Patch pipettes had resistance of 6-8 $\mathrm{M} \Omega$ when filled with the preceding solution. A $5 \mathrm{mV}$ hyperpolarizing test pulse was applied every $5 \mathrm{~s}$ to monitor the changes of the series resistance and the process of perforation. Stable series resistances (50-70 $\mathrm{M} \Omega$ ) were usually obtained $\sim 30 \mathrm{~min}$ after the formation of gigaohm seals. For those cells showing abrupt reduction in series resistance during membrane perforation suggesting the simultaneous formation of whole-cell configuration, experiments were terminated immediately. Perforated-patch configurations were verified by examining the series resistance again at the end of the experiments. Data were included for analysis only from those cells showing $<15 \%$ alteration of series resistance.

Recordings of calcium and potassium currents from identified stellate neurons in the entorhinal cortex. Depolarizing voltage sag in response to hyperpolarizing current injections and $\mathrm{K}^{+}$channel currents were recorded from stellate neurons in layer II of the entorhinal cortex using $\mathrm{K}^{+}$-containing intracellular solution comprising (in $\mathrm{mM}$ ) 100 K-gluconate, 0.6 EGTA, $5 \mathrm{MgCl}_{2}, 8 \mathrm{NaCl}$, 40 HEPES, 2 MgATP, 0.3 $\mathrm{NaGTP}, 0.1$ leupeptin, 20 phosphocreatine and $50 \mathrm{U} / \mathrm{ml}$ phosphocreatine kinase, $\mathrm{pH} 7.3 . \mathrm{K}^{+}$currents were isolated by including, in the above extracellular solution, TTX $(0.5 \mu \mathrm{M})$ to block $\mathrm{Na}^{+}$channels and $\mathrm{CdCl}_{2}$ $(100 \mu \mathrm{M})$ to block $\mathrm{Ca}^{2+}$ channels. $\mathrm{Ca}^{2+}$ currents were recorded with intracellular solution containing (in $\mathrm{mM}$ ) Cs-gluconate $100, \mathrm{NaCl} 5$, $\mathrm{MgCl}_{2} 2, \mathrm{CaCl}_{2}$ 0.5, TEA-Cl 20, EGTA 2, HEPES 10, phosphocreatine 20, phosphocreatine kinase $50 \mathrm{U} / \mathrm{ml}, \mathrm{MgATP} 2$, NaGTP 0.1 and leupeptin $0.1, \mathrm{pH}$ 7.3. The extracellular solution was supplemented with $10 \mathrm{~mm}$ TEA-Cl and $0.5 \mu \mathrm{M}$ TTX. $\mathrm{Ca}^{2+}$ currents were induced by depolarization from -70 to $0 \mathrm{mV}$ for $200 \mathrm{~ms}$.

Tissue culture. Primary hippocampal neurons were cultured from embryonic C57BL/6 mice at $16 \mathrm{~d}$ of gestation. Briefly, the pregnant mice were killed by asphyxiation with $\mathrm{CO}_{2}$ and the fetuses were removed and decapitated. The hippocampi were isolated and incubated with $0.25 \%$ trypsin-EDTA for $10 \mathrm{~min}$, dissociated by trituration with fire-polished glass pipettes, and plated on poly-D-lysine-coated glass-bottom $35 \mathrm{~mm}$ tissue culture dishes. Neurons were grown in Neurobasal medium with L-glutamine, $100 \mathrm{U} / \mathrm{ml}$ penicillin, $0.1 \mathrm{mg} / \mathrm{ml}$ streptomycin, $0.25 \mu \mathrm{g} / \mathrm{ml}$ amphotericin $\mathrm{B}$ and $\mathrm{B} 27$ supplement (Invitrogen) at $37^{\circ} \mathrm{C}$ in $5 \% \mathrm{CO}_{2}$ for 11-14 d before experiments.

Calcium image. Cultured hippocampal neurons were loaded with Fura-2 AM $(1 \mu \mathrm{M})$ and then washed twice with prewarmed HBSS buffer ( $5 \mathrm{~mm} \mathrm{KCl}, 125 \mathrm{~mm} \mathrm{NaCl}, 1 \mathrm{~mm} \mathrm{MgCl}_{2}$, 25 mм HEPES, 5 mм glucose, 1 $\mathrm{mg} / \mathrm{ml} \mathrm{BSA}, \mathrm{pH}$ 7.4). The neurons were bathed in the extracellular solu- 
A

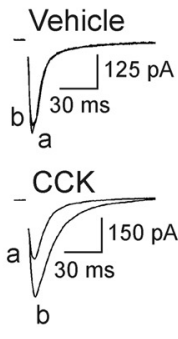

D

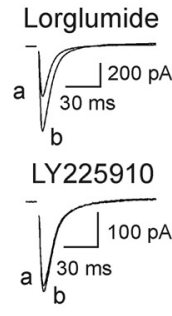

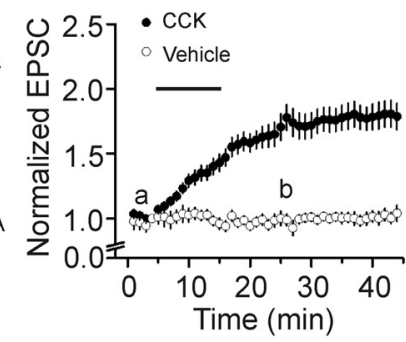

$\mathrm{E}$

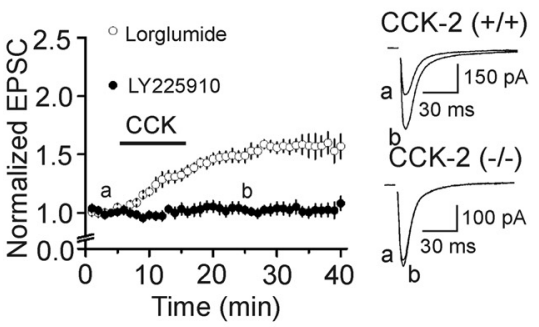

B

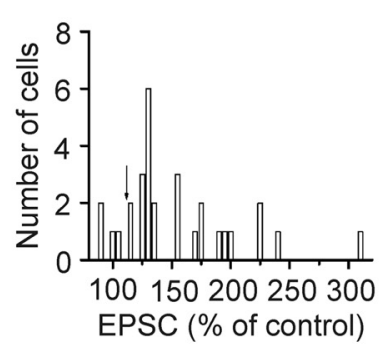

C

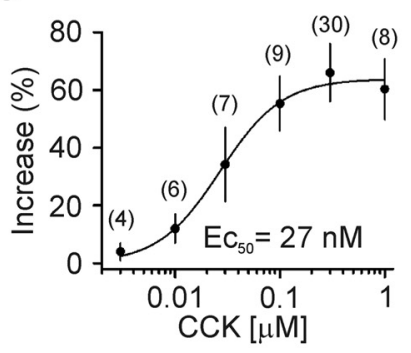

$\mathrm{F}$

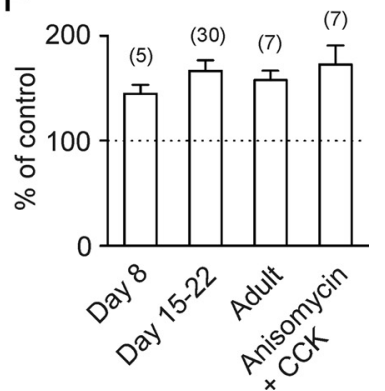

Figure 1. CCK increases AMPA EPSCs at hippocampal synapses via CCK-2 receptors. $A$, Bath application of CCK increased AMPA EPSCS at PP-GC synapses whereas application of vehicle (0.004\% $\mathrm{NH}_{4} \mathrm{OH}$ ) had no effects. The vertical axis was truncated to show the magnitude of the effect of CCK. Left panel shows the current traces averaged from 10 AMPA EPSCs before $(\boldsymbol{a})$ and after ( $\boldsymbol{b}$ ) application of vehicle (top) or CCK (bottom). $\boldsymbol{B}$, Amplitude distribution of AMPA EPSCs recorded at PP-GC synapses. Arrow indicates the criterion used to separate the responsive and the unresponsive synapses. $C$, Concentration-response curve of CCK by plotting the percentage of increases in the amplitudes of AMPA EPSCs recorded at the PP-GC synapses versus the concentrations of CCK. Numbers in the parenthesis are numbers of cells examined. D, Application of CCK-2 receptor antagonist, LY225910 (1 $\mu \mathrm{M})$, not CCK-1 receptor antagonist, lorglumide (1 $\mu \mathrm{M})$, blocked CCK-induced increases in AMPA EPSCs. Left, Top, Current traces averaged from 10 AMPA EPSCs in the presence of lorglumide alone $(\boldsymbol{a})$ and after coapplication of CCK (b). Left, Bottom, Current traces averaged from $10 \mathrm{AMPA}$ EPSCs in the presence of LY225910 alone $(\boldsymbol{a})$ and after coapplication of $C(K(\boldsymbol{b})$. $\boldsymbol{E}$, Application of CCK increased AMPA EPSCs recorded from 11 cells in slices cut from 3 wild-type $[C C K-2(+/+)]$ mice whereas CCK failed to change AMPA EPSCs recorded from 13 cells in slices cut from 4 knock-out [CCK-2(-/-)] mice. Left panel shows the current traces averaged from 10 AMPA EPSCs before (a) and after ( $\boldsymbol{b}$ ) application of CCK from wild-type (top) and knock-out (bottom) mice. $\boldsymbol{F}$, There were no age-dependent changes in CCK-mediated increases in AMPA EPSCs and application of the transcriptional inhibitor, anisomycin $(25 \mu \mathrm{M})$, failed to block CCK-induced increases in AMPA EPSCs. Numbers on the top of the bars indicate the number of cells recorded.

tion containing $d l$-APV $(50 \mu \mathrm{M})$, DNQX $(10 \mu \mathrm{M}), \mathrm{Cd}^{2+}(100 \mu \mathrm{M})$ and TTX $(0.5 \mu \mathrm{M})$ to block the effects of CCK on synaptic transmission. Cells were excited alternatively at 340 and $380 \mathrm{~nm}$ and images were captured at $510 \mathrm{~nm}$ with an Axiocam MRm camera (Carl Zeiss GmbH). Background fluorescence was subtracted from total fluorescence measured. The intracellular calcium concentration was determined using the formula: $\left[\mathrm{Ca}^{2+}\right]_{\mathrm{i}}=K_{\mathrm{d}} \times\left(\left(R-R_{\min }\right) /\left(R_{\max }-R\right)\right) \times \beta$, after establishing the values for $R_{\min }=0.17, R_{\max }=3.53, \beta=4.86$, and $K_{\mathrm{d}}=140 \mathrm{~nm}$ by using in vitro standard calibration curves (Invitrogen) and validating the fitting by in situ calibration with the $\mathrm{Ca}^{2+}$ ionophore 4-bromo-A23187 (10 $\mu \mathrm{M}$, Invitrogen) in HBSS with known concentrations of $\mathrm{Ca}^{2+}$.

Breeding and genotyping of mutant mice. Heterozygous mating pairs (F1 hybrid crosses from 129 PLC- $\beta 1^{+/-} \times$C57BL/6 PLC $\beta 1^{+/-}$) were used to derive wild-type, heterozygous and homozygous pups for experimental analysis. PCR genotyping from purified genomic DNA was performed as described previously (Kim et al., 1997; Deng et al., 2006). Detailed methods for the generation and genotyping of homozygous knock-out mice for CCK-2 receptors (Nagata et al., 1996), PKC $\alpha$ (Leitges et al., 2002) and PKC $\beta$ (Leitges et al., 1996) were described previously. Homozygous PKC $\gamma$ knock-out mating pairs (002466B6; 129P2Prkcc $<\mathrm{tm} 1 \mathrm{Stl}>/ \mathrm{J}$ ) were purchased from The Jackson Laboratory. Pups derived from these homozygous mating pairs were bred in the animal facility of the University of North Dakota and used for experiments.

Data analysis. Data are presented as the means \pm SEM. Concentration-response curve of CCK was fit by Hill equation: $I=I_{\max } \times\{1 /[1+$ $\left.\left.\left(\mathrm{EC}_{50} /[\text { ligand }]\right)^{n}\right]\right\}$, where $I_{\max }$ is the maximum response, $\mathrm{EC}_{50}$ is the concentration of ligand producing a half-maximal response, and $n$ is the Hill coefficient. Student's paired or unpaired $t$ test or ANOVA was used for statistical analysis as appropriate; $\mathrm{P}$ values are reported throughout the text and significance was set as $p<0.05$. N numbers in the text represent the number of cells examined unless stated otherwise.

\section{Results}

\section{CCK increases excitatory synaptic transmission at} hippocampal synapses

Whereas application of CCK or a CCK-2 receptor agonist has been shown to increase glutamate release in the perfusate of hippocampal slices (Migaud et al., 1994) and in purified rat hippocampal synaptosomes (Breukel et al., 1997), these experiments did not address the synapse type(s) at which CCK facilitates glutamate release. We therefore initially asked at which synapse(s) CCK increases glutamate release in the hippocampus. Afferents from the entorhinal cortex (perforant path) make glutamatergic synapses onto dentate gyrus granule cells (PP-GC synapse) and the highest density of CCK receptors are detected in the region adjacent to the granule cell layer (Kritzer et al., 1988). We recorded, from dentate gyrus granule cells, AMPA receptormediated EPSCs evoked by placing a stimulation electrode in the middle to the inner one third of the molecular layer of the dentate gyrus to stimulate the medial perforant path. Bath application of the sulfated CCK octapeptide (CCK-8S, $0.3 \mu \mathrm{M}$ ) increased AMPA EPSCs to $166 \pm 10 \%$ of control $(n=30, p<0.001$, paired $t$ test, Fig. $1 A)$ whereas application of the vehicle $\left(0.004 \% \mathrm{NH}_{4} \mathrm{OH}\right.$ in the extracellular solution) used to dissolve CCK did not significantly change AMPA EPSCs ( $98 \pm 5 \%$ of control, $n=8, p=0.78$, Fig. 1A).

Figure $1 B$ shows the distribution of the effect of CCK on the peak of AMPA EPSCs. Because the normal variation of the averaged AMPA EPSC was $\sim 10 \%$ under our recording conditions, we defined cells exhibiting a response $>115 \%$ of control as re- 
sponsive cells (Fig. 1B). By this criterion, $87 \%$ of the cells at the PP-GC synapses were responsive. AMPA EPSC amplitudes began to increase in $<5 \mathrm{~min}$ after the beginning of CCK application, but it took $\sim 15-20 \mathrm{~min}$ to observe the maximal effect of CCK. The maximal effect of CCK was independent of the duration of CCK application because application of CCK for $3 \mathrm{~min}$ (time required for complete solution exchange in the recording chamber) still significantly augmented AMPA EPSCs to $159 \pm 11 \%$ of control $(n=8, p<0.001$, data not shown) after 30 min washing in CCK-free external solution. The holding current before and during the application of CCK was not significantly altered (111 \pm $9 \%$ of control, $n=26, p=0.23$, data not shown) suggesting that CCK had no effects on the resting membrane potential of the recorded cells under our recording conditions. CCK dosedependently increased AMPA EPSCs recorded at the PP-GC synapses with an $\mathrm{EC}_{50}$ value of $27 \mathrm{~nm}$ (Fig. 1C), a value close to that obtained from binding experiments (Van Dijk et al., 1984).

We also examined the effects of CCK on other three hippocampal synapses: mossy fiber-CA3, CA3-CA3 and CA3-CA1 pyramidal neuron synapses. Application of CCK in the concentration range of 0.03 to $3 \mu \mathrm{M}$ failed to alter significantly AMPA EPSCs at the mossy fiber-CA3 synapses (supplemental Fig. $\mathrm{S} 1 A_{1}, A_{2}$, available at www.jneurosci.org as supplemental material). However, application of CCK significantly increased AMPA EPSCs in 74\% of the cells at the CA3-CA3 (supplemental Fig. $\mathrm{S} 1 B_{1}, B_{2}$, available at www.jneurosci.org as supplemental material) and $65 \%$ of the cells at the CA3-CA1 (supplemental Fig. $\mathrm{S}_{1} \mathrm{C}_{1}, C_{2}$, available at www.jneurosci.org as supplemental material) pyramidal neuron synapses. These results demonstrate that CCK increases AMPA receptor-mediated synaptic transmission at PP-GC, CA3-CA3 and CA3-CA1 synapses with no effects at mossy fiber-CA3 pyramidal neuron synapses. The highest responsive ratio was found at PP-GC synapses, consistent with previous immunostaining results showing that the highest density of CCK receptors is in the dentate gyrus, but moderate expressions of CCK receptors are in CA3 and CA1 area (Kritzer et al., 1988). Because the highest responsive ratio to CCK was observed at the medial PP-GC synapses, we recorded AMPA EPSCs at this synapse for the rest of the experiments to further determine the involved cellular and molecular mechanisms.

CCK increases AMPA EPSCs via activation of CCK-2 receptors Whereas CCK-8S is the major form of CCK in the brain (Rehfeld et al., 1985; You et al., 1994), we also examined the effects of the unsulfated CCK octapeptide (CCK-8U). Application of CCK-8U $(0.3 \mu \mathrm{M})$ increased AMPA EPSCs to $164 \pm 23 \%$ of control $(n=$ $11, p=0.02$, data not shown). Because CCK-8U is a weak agonist for CCK-1 receptors, but it is almost as potent as CCK-8S for CCK-2 receptors (Wank, 1995), these results suggest the involvement of CCK-2 receptors. We further tested the role of CCK-2 receptors. Application of a CCK-2 receptor antagonist, LY225910 $(1 \mu \mathrm{M})$ (Yu et al., 1991) alone did not significantly alter AMPA EPSCs (101 $\pm 5 \%$ of control, $n=10, p=0.79$, data not shown), but blocked CCK-mediated increases in AMPA EPSCs (104 \pm $5 \%$ of control, $n=10, p=0.43$, Fig. $1 D)$. Similarly, application of another CCK-2 receptor inhibitor, YM022 (1 $\mu \mathrm{M})$ (Nishida et al., 1994 ) alone did not significantly change AMPA EPSCs ( $95 \pm 7 \%$ of control, $n=10, p=0.51)$, but blocked CCK-induced increases in AMPA EPSCs ( $98 \pm 7 \%$ of control, $n=10, p=0.78$, data not shown). However, application of a selective CCK-1 receptor antagonist, lorglumide (1 $\mu \mathrm{M})$ (de Tullio et al., 1999), did not block CCK-induced increases in AMPA EPSCs $(157 \pm 10 \%$ of control, $n=6, p=0.002$, Fig. $1 D$ ). We further used the CCK-2 receptor knock-out (KO) mice (Nagata et al., 1996) and tested the role of CCK-2 receptors. Application of CCK failed to change AMPA EPSCs recorded from 13 cells in slices cut from 4 CCK-2 receptor $\mathrm{KO}$ mice $(p=0.6$, Fig. $1 E)$ whereas it significantly increased AMPA EPSCs recorded from 11 cells in slices cut from 3 wildtype mice ( $p=0.001$, Fig. $1 E$ ). All these results unanimously demonstrate that the effects of CCK on AMPA EPSCs are mediated by CCK-2 receptors.

\section{CCK-mediated increases in AMPA EPSCs are not modulated developmentally or transcriptionally}

The above experiments were performed in slices cut from 15- to 22-d-old rats simply because rats of this age produce better slices. Because we previously observed that CCK-mediated modulation of GABA release was limited to juvenile rats $(<31 \mathrm{~d})$ (Deng and Lei, 2006), we also examined whether CCK-mediated increases in AMPA EPSCs were developmentally regulated. We extended the age of the rats to $8 \mathrm{~d}$ after birth and adult ( $>2$ months). CCK still increased AMPA EPSCs to the same extent at these ages (Fig. $1 F$, $p>0.05$ for each group) suggesting that CCK-mediated increases in AMPA EPSCs are not developmentally modulated. Because it took $\sim 15$ min to observe the maximal effect of CCK, we examined whether protein synthesis was required for the effects of CCK. We pretreated slices with a transcription inhibitor, anisomycin $(25 \mu \mathrm{M})$, and the same concentration of anisomycin was bath-applied. Application of CCK in the presence of anisomycin still increased AMPA EPSCs to $172 \pm 18 \%$ of control $(n=7, p=$ 0.007 , Fig. $1 F$ ) suggesting that protein synthesis is not required for CCK-mediated increases in AMPA EPSCs.

\section{CCK facilitates presynaptic glutamate release}

The effects of CCK could be attributable to an increase in presynaptic glutamate release or to an upregulation of postsynaptic AMPA receptor function. We next differentiated between the presynaptic and postsynaptic effects of CCK. First, we calculated the coefficient of variation (CV) of AMPA EPSCs recorded before and during the application of CCK because changes in presynaptic transmitter release are usually concomitant with an alteration in CV. CCK significantly reduced the value of CV (Fig. 2A). Second, we compared the paired-pulse ratio (PPR) before and during the application of CCK. CCK significantly reduced PPR (Fig. $2 B$ ). These results indicate that CCK increases AMPA EPSCs by facilitating presynaptic glutamate release.

We next probed whether CCK facilitates glutamate release via activation of presynaptic or postsynaptic CCK-2 receptors at the $\mathrm{PP}-\mathrm{GC}$ synapses because it is still possible that CCK interacts with postsynaptic CCK-2 receptors to generate some retrograde messengers to enhance glutamate release. If so, intracellular application of GDP- $\beta$-S, a G-protein inactivator, should block CCK-mediated increases in AMPA EPSCs. We therefore included GDP- $\beta$-S ( $4 \mathrm{~mm}$ ) in the recording pipettes and waited for $>25$ min after the formation of whole-cell configuration. Under this condition, application of CCK still increased AMPA EPSC amplitudes significantly ( $149 \pm 7 \%$ of control, $n=8, p<0.001$, supplemental Fig. S2 A, available at www.jneurosci.org as supplemental material). To exclude the possibility that the incapability of GDP$\beta$-S to block CCK-induced increases in AMPA EPSCs was due to the loss of the biological activity of GDP- $\beta$-S, we performed a positive control experiment. As would be demonstrated below (see Fig. 5E), bath application of CCK inhibited the delayed rectifier $\mathrm{K}^{+}$channels $\left(I_{\mathrm{K}}\right)$ recorded from the stellate neurons in layer II of the entorhinal cortex in slices. Intracellular application of GDP- $\beta$-S (4 mM) blocked CCK-induced depression of $I_{\mathrm{K}}(n=5$, 

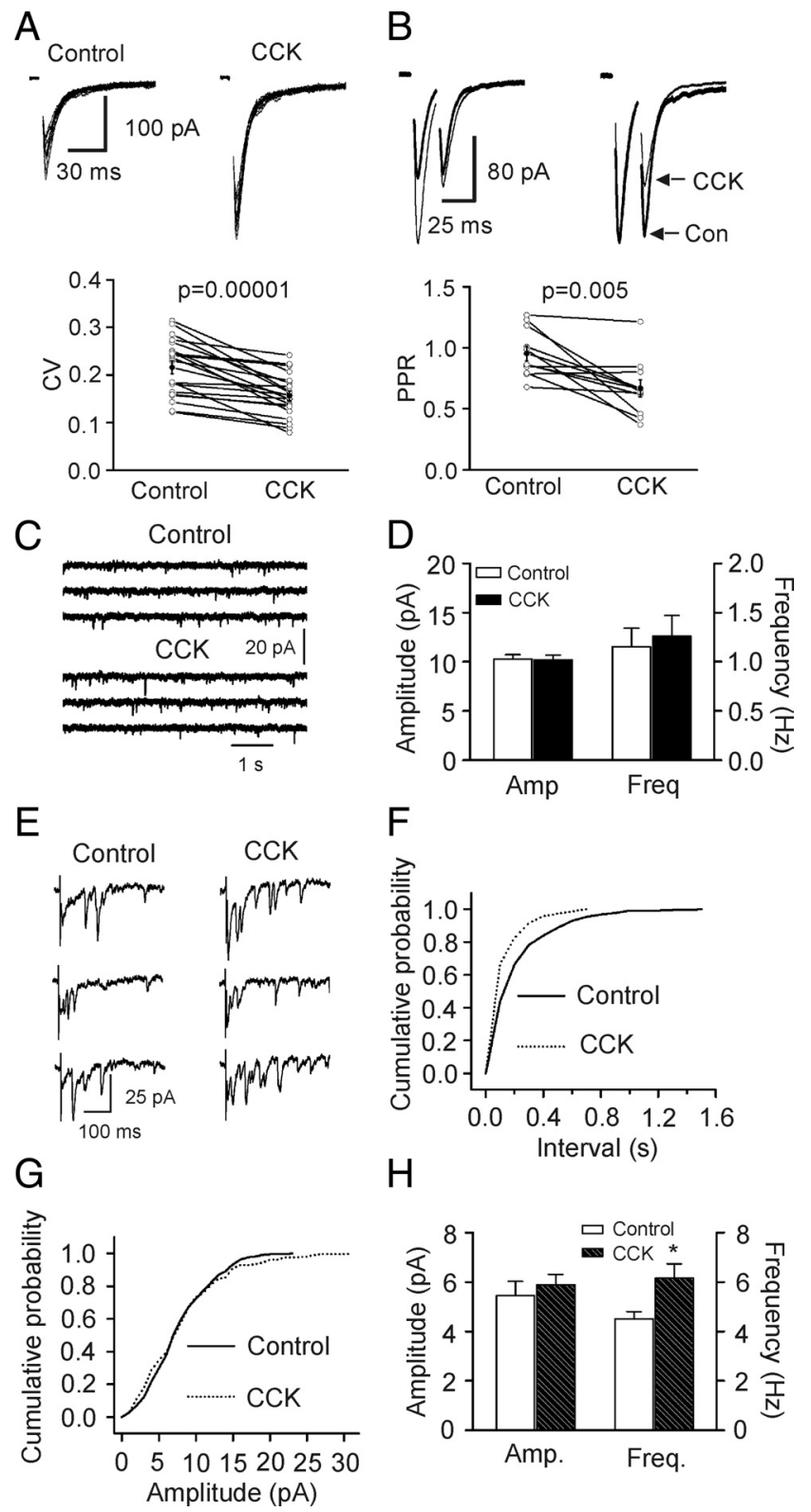

$\mathrm{H}$

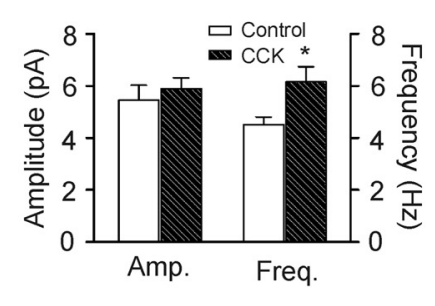

Figure 2. CCK facilitates presynaptic glutamate release by increasing quantal content. $A$, CCK reduced the coefficient of variation (CV $=S D$ /mean) of AMPA EPSCS. SD and mean were obtained by averaging 15 consecutive EPSCs. Top shows 15 consecutive EPSCs recorded before (left) and during (right) the application of CCK. Bottom shows the calculated CVs from 20 cells (open circles) and their averages (solid circles). $B$, CCK reduced pairedpulse ratio (PPR $=P 2 / P 1, P 1$ and $P 2$ are the EPSCs evoked by two stimuli at an interval of $20 \mathrm{~ms}$ ). Top left, EPSCs averaged from 20 to 30 current traces before (bold) and during (thin) the application of CCK. Top right, EPSCs recorded before (bold) and during (thin) application of CCK were scaled to the first EPSC. Note that the second EPSC during the application of CCK is smaller than control. Bottom, PPRs recorded from 11 cells (open circles) and their averages (solid circles). $C$, mEPSCs recorded in the presence of TTX before and during the application of CCK. D, Summarized mEPSC frequency and amplitude ( $n=$ 20). $\boldsymbol{E}$, Evoked AMPA EPSCs recorded from the same synapse in the presence of $\mathrm{Sr}^{2+}$ $(6 \mathrm{mM})$ before and during application of CCK. Note that AMPA EPSCs recorded as asynchronous events in the extracellular solution containing $\mathrm{Sr}^{2+}$. Also note that application of CCK increased the frequency of asynchronous events recorded in the presence of $\mathrm{Sr}^{2+}$. $F$, Cumulative frequency distribution of asynchronous EPSCs in the presence of $\mathrm{Sr}^{2+}$ before and during the application of CCK. G, Cumulative amplitude distribution of asynchronous EPSCs in the presence of $\mathrm{Sr}^{2+}$ before and during the application of CCK. $\boldsymbol{H}$, Summarized asynchronous EPSC frequency and amplitude $(n=7)$. $p=0.89$, supplemental Fig. S2 B, available at www.jneurosci.org as supplemental material). Together, these results suggest that CCK increases glutamate release via activation of presynaptic CCK-2 receptors. Consistent with our electrophysiological results, enriched CCK-binding sites have been detected in layer II of the entorhinal cortex where the cell bodies of the perforant pathway reside in (Köhler and Chan-Palay, 1988).

CCK increases quantal content with no effects on quantal size We then tested whether CCK-mediated increases in glutamate release are AP-dependent or not by recording AMPA receptormediated miniature EPSCs (mEPSCs) in the presence of TTX. Bath application of CCK did not change the frequency $(n=20$, $p=0.37)$ or the amplitude $(n=20, p=0.84$, Fig. $2 C, D)$ of mEPSCs suggesting that CCK-mediated increases in glutamate release are AP-dependent. However, we cannot exclude the possibility that the effect of CCK on mEPSCs is diluted by the fact that mEPSCs are originated from all the glutamatergic terminals impinging on the recorded cell.

We next measured the effects of CCK on the quantal properties of glutamate release at the PP-GC synapses using the method of replacing extracellular $\mathrm{Ca}^{2+}$ with strontium $\left(\mathrm{Sr}^{2+}\right)$ to induce asynchronous transmitter release (Goda and Stevens, 1994; Oliet et al., 1996). After forming whole-cell recordings, AMPA EPSCs evoked by stimulation of perforant path in the presence of extracellular $\mathrm{Ca}^{2+}$ were initially recorded. To avoid the confounding effects of spontaneous EPSCs on the asynchronous events when extracellular $\mathrm{Ca}^{2+}$ was replaced with $\mathrm{Sr}^{2+}$, experiments were limited to those cells exhibiting spontaneous events $<0.5 \mathrm{~Hz}$. The extracellular $\mathrm{Ca}^{2+}$ was then replaced by $\mathrm{Sr}^{2+}(6 \mathrm{~mm})$ to induce asynchronous release from the same synapse. After recording sufficient events to analyze the quantal properties in control, we applied CCK in the extracellular solution containing the same concentration of $\mathrm{Sr}^{2+}$ for $20 \mathrm{~min}$ to observe the maximal effect of $\mathrm{CCK}$. We then recorded the asynchronous events in the presence of $\mathrm{Sr}^{2+}$ and CCK. The results are shown in Figure $2 E-H$. When extracellular $\mathrm{Ca}^{2+}$ was replaced by $\mathrm{Sr}^{2+}$, asynchronous release occurred and CCK significantly increased the frequency of asynchronous EPSCs (control: $4.5 \pm 0.3 \mathrm{~Hz}, \mathrm{CCK}: 6.2 \pm 0.6 \mathrm{~Hz}, n=7$, $p=0.01$, Fig. $2 E, F, H)$ without altering the amplitude of asynchronous EPSCs (control: $5.5 \pm 0.6 \mathrm{pA}$, CCK: $5.9 \pm 0.4 \mathrm{pA}, n=7, p=$ 0.21 , Fig. $2 E, G, H)$ suggesting that CCK increases quantal content without altering quantal size.

CCK increases the number of releasable vesicles and release probability without changing the rate of recovery from vesicle depletion

Increases in presynaptic transmitter release can result from an increase in the number of readily releasable quanta (synaptic vesicles) $(N)$ or an increase in release probability $\left(P_{r}\right)$. We next used the method of high-frequency stimulation (Schneggenburger et al., 1999; Taschenberger et al., 2002) to evaluate CCK-induced changes in $N$ and $P_{r}$. This method is based on the assumption that high-frequency stimulation induced depression is primarily caused by the depletion of readily releasable quanta which could be estimated by calculating the cumulative EPSC amplitude for time intervals that are short with respect to the time required for recovery from depression. The zero time intercept of a line fitted to a cumulative amplitude plot of EPSCs equals to the product of $N$ and the quantal size $(q) . P_{r}$ can be estimated from the first EPSC amplitude divided by $N q$. To exclude potential contaminations from the activation of other receptors, we included, in the extracellular solution, a "cocktail" of inhibitors to block 
NMDA (dl-APV, $100 \mu \mathrm{M}$ ), metabotropic glutamate (MCPG, 1 $\mathrm{mM})$, kainate (UBP296, $10 \mu \mathrm{M}), \mathrm{GABA}_{\mathrm{A}}$ (bicuculline, $10 \mu \mathrm{M}$ ), $\mathrm{GABA}_{\mathrm{B}}(\mathrm{CGP} 55845,5 \mu \mathrm{M})$, cannabinoid (AM 251, $10 \mu \mathrm{M}$ ), muscarinic (atropine, $10 \mu \mathrm{M}$ ), nicotinic (mecamylamine, $100 \mu \mathrm{M}$ ) and adenosine $\left(\mathrm{A}_{1}\right.$, DPCPX, $1 \mu \mathrm{M} ; \mathrm{A}_{2 \mathrm{~A}}, \mathrm{SCH} 442416,1 \mu \mathrm{M} ; \mathrm{A}_{2 \mathrm{~B}}$, MRS1706, $1 \mu \mathrm{M} ; \mathrm{A}_{3}$, MRS1220, $\left.10 \mu \mathrm{M}\right)$ receptors. Figure $3 A$ shows the EPSC trains evoked by 20 stimuli at $40 \mathrm{~Hz}$ before and during the application of CCK. The average data from 6 cells for the 20 stimuli are shown in Figure $3 B$. Figure $3 C$ shows the $\mathrm{cu}-$ mulative amplitude histogram. CCK increased $N q$ by $26 \pm 6 \%$ $(n=6, p=0.02$, Fig. $3 D)$ and $P_{r}$ by $34 \pm 6 \%(n=6, p<0.001$, Fig. $3 E$ ). Because CCK did not change quantal size (q) (Fig. 2), these results suggest that CCK increases both the number of readily releasable quanta $(N)$ and release probability $\left(P_{r}\right)$.

Increases in the number of readily releasable quanta can occur with or without a concomitant increase in the rate of vesicle replenishment. We next tested whether CCK increases the rate of recovery from vesicle depletion. We used a protocol comprising a train of stimulation $(40 \mathrm{~Hz}, 20$ stimuli) to deplete the readily releasable pool followed by a test pulse at various intervals $(0.1 \mathrm{~s}$, $0.5 \mathrm{~s}, 1 \mathrm{~s}, 2 \mathrm{~s}, 5 \mathrm{~s}, 10 \mathrm{~s}$ ) to evaluate the replenishment of synaptic vesicles from depletion (Fig. $3 F$ ). The time course of recovery after the $40 \mathrm{~Hz}$ train could be fitted by a single exponential function with a time constant of $3.6 \pm 1.0 \mathrm{~s}$ before and $3.7 \pm 1.1 \mathrm{~s}$ during the application of CCK $(n=6, p=0.96$, Fig. $3 G)$ indicating that CCK does not increase the rate of recovery from vesicle depletion.

CCK does not directly modulate voltage-dependent $\mathrm{Ca}^{2+}$ channels We next examined the ionic mechanisms underlying CCKinduced increases in glutamate release. We first examined whether CCK facilitates glutamate release by increasing $\mathrm{Ca}^{2+}$ channel function, although CCK slightly inhibits $\mathrm{Ca}^{2+}$ channels in CA1 pyramidal neurons (Shinohara and Kawasaki, 1997). P/Q-type $\mathrm{Ca}^{2+}$ channels are the predominant $\mathrm{Ca}^{2+}$ channels involved in transmitter release whereas $\mathrm{N}$-type $\mathrm{Ca}^{2+}$ channels contribute a small amount of $\mathrm{Ca}^{2+}$ for glutamate release at PP-GC synapses (Qian and Noebels, 2001). If CCK increases glutamate release by directly enhancing $\mathrm{Ca}^{2+}$ channel function, application of specific P/Q- or N-type $\mathrm{Ca}^{2+}$ channel inhibitors would block the effects of CCK. We therefore used toxins specific for those two types of $\mathrm{Ca}^{2+}$ channels and examined their roles in CCK-mediated increases in glutamate release. Application of P/Q-type $\mathrm{Ca}^{2+}$ channel inhibitor, $\omega$-agatoxin TK $(250 \mathrm{nM})$ inhibited AMPA EPSCs to $28 \pm 4 \%$ of control $(n=6, p<0.001)$ and subsequent application of CCK still increased AMPA EPSCs to $161 \pm 13 \%$ of control $(n=6, p=0.006$, Fig. $4 A)$. Application of N-type $\mathrm{Ca}^{2+}$ channel inhibitor, $\omega$-conotoxin GVIA (250 nM) inhibited AMPA EPSCs to $77 \pm 4 \%$ of control $(n=6, p=0.004)$ and subsequent application of CCK increased AMPA EPSCs to $148 \pm 13 \%$ of control $(n=6, p=0.02$, Fig. $4 B)$. CCK-induced increases in AMPA EPSCs in the presence of $\omega$-agatoxin TK or $\omega$-conotoxin GVIA were not significantly different from the effect of CCK in the absence of those toxins ( $p>0.05$, Students' unpaired $t$ test). Application of both toxins completely blocked transmitter release (inhibition by $98 \pm 3 \%, n=3$ ) suggesting that it is unlikely that other types of $\mathrm{Ca}^{2+}$ channels are involved. These results suggest that CCK is not acting selectively on P/Q- or $\mathrm{N}$-type $\mathrm{Ca}^{2+}$ channels.

If CCK acts on both types of $\mathrm{Ca}^{2+}$ channels, blocking one type would still permit CCK to interact with the other to increase glutamate release. To test this possibility, we directly recorded $\mathrm{Ca}^{2+}$ channel currents $\left(I_{\mathrm{Ca}}\right)$ from identified stellate neurons in
A

Control

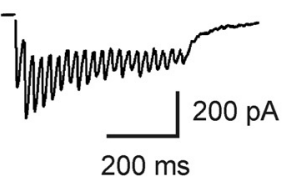

B

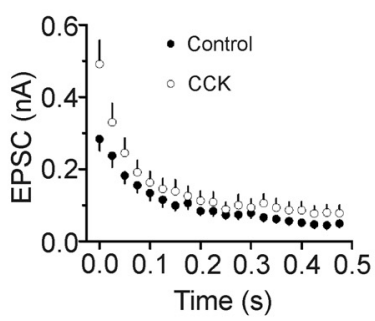

$\mathrm{D}$

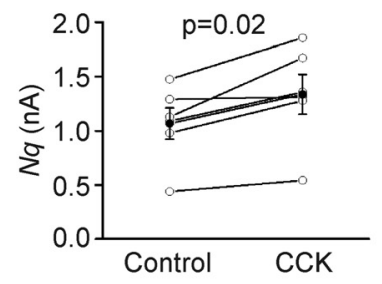

$\mathrm{F}$

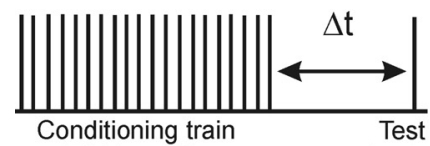
$(40 \mathrm{~Hz} \times 20)$
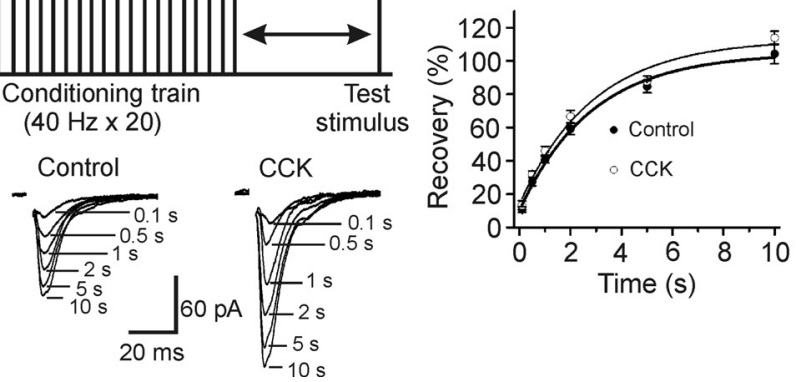

Figure 3. CCK increases the number of releasable vesicles and release probability without changing the rate of recovery from vesicle depletion. $\boldsymbol{A}$, EPSC trains averaged from 15 traces evoked by 20 stimuli at $40 \mathrm{~Hz}$ before (left) and during (right) the application of CCK. Stimulation artifacts were blanked for clarity. $\boldsymbol{B}$, EPSC amplitudes averaged from 6 cells in response to 20 stimuli at $40 \mathrm{~Hz}$ before and during the application of CCK. The amplitude of EPSC evoked by each stimulus was measured by resetting the base line each time at a point within $0.5 \mathrm{~ms}$ before the beginning of each stimulation artifact. C, Cumulative amplitude histogram of EPSCs. For each cell, the last 6 EPSC amplitudes were fit with a linear regression line and extrapolated to time 0 to estimate the readily releasable pool size $(N q)$. $\boldsymbol{D}$, CCK increases $N q(n=6)$. $\boldsymbol{E}$, CCK increases release probability $\left(P_{r} n=6\right)$. For each cell, $P_{r}$ was calculated as the ratio of the first EPSC amplitude divided by its $\mathrm{Nq}$ obtained by linear fitting of the cumulative EPSC histogram. F, Top, Experimental protocol. A conditioning train (20 stimuli at $40 \mathrm{~Hz}$ ) was followed by a test stimulus at various intervals $(\Delta t=0.1-10 \mathrm{~s})$. This protocol was repeated every 30 s. Bottom, EPSCs evoked by the test pulse from the same synapse at different intervals were aligned and superimposed before (left) and during (right) application of CCK. Stimulation artifacts were blanked for clarity. $G$, time course of recovery from depletion before and during the application of CCK expressed as percentage recovery $=\left(I_{\text {test }}-I_{\mathrm{sS}}\right) /\left(I_{\text {first }}-I_{\mathrm{ss}}\right) \times 100$, where $I_{\text {test }}$ is the EPSC evoked by the test pulse, $I_{\mathrm{ss}}$ is the steady-state current left after the conditioning train (the average of the last 5 EPSC evoked by the conditioning train), $I_{\text {first }}$ is the EPSC evoked by the first stimulus of the conditioning train. Data before (thick line) and during (thin line) the application of CCK from 6 cells were fit by a single exponential function.

layer II of the entorhinal cortex, the cell bodies of the perforant path. The horizontal slices contain both the hippocampus and the entorhinal cortex. Stellate neurons were identified by their morphology and electrophysiological properties described previ- 
ously (Deng and Lei, 2007; Deng et al., 2007, 2009). Stellate neurons have larger and polygonal soma with variable number of main dendrites radiating out from the cell bodies, but are devoid of an evidently dominant dendrite. These neurons show an electrophysiological property, i.e., hyperpolarizing current pulse injections always caused the membrane potential to attain an early peak and then "sag" to a steady-state level (Fig. 4C). Application of CCK failed to modulate $I_{\mathrm{Ca}}(106 \pm 5 \%$ of control, $n=6, p=0.26$, Fig. $4 D$ ). We also examined the effects of CCK on isolated $\mathrm{N}$ - and P/Q-type $I_{\mathrm{Ca}}$ recorded from stellate neuron soma. Application of $\omega$-agatoxin TK $(250 \mathrm{~nm})$ reduced $I_{\mathrm{Ca}}$ to $41 \pm 3 \%$ of control $(n=6, p<0.001$, Fig. $4 E)$. Subsequent application of CCK failed to further change $I_{\mathrm{Ca}}(95 \pm 2 \%$ of control, $n=6, p=0.12$, Fig. $4 E$ ). Similarly, application of $\omega$-conotoxin GVIA $(250 \mathrm{nM})$ reduced $I_{\mathrm{Ca}}$ to $75 \pm 3 \%$ of control $(n=7, p<0.001$, Fig. $4 F)$ and CCK did not significantly change $I_{\mathrm{Ca}}$ after application of $\omega$-conotoxin GVIA ( $96 \pm 2 \%$ of control, $n=7, p=0.06$, Fig. $4 F)$. All those data strongly indicate that CCK does not directly modulate $\mathrm{Ca}^{2+}$ channels.

\section{CCK inhibits $\mathrm{K}^{+}$channels to increase glutamate release}

We then examined the roles of $\mathrm{K}^{+}$channels. If CCK inhibits $\mathrm{K}^{+}$ channels resulting in an increase in $\mathrm{Ca}^{2+}$ influx, transmitter release can also be increased. Because the types of $\mathrm{K}^{+}$channels expressed on the axons of perforant path and the soma of the stellate neurons in layer II of the entorhinal cortex are Kv1 subtypes (Monaghan et al., 2001) that are sensitive to 4-aminopyridine (4-AP) (Coetzee et al., 1999), we used 4-AP to examine the roles of $\mathrm{K}^{+}$channels in CCK-mediated increases in glutamate release. Application of 4-AP $(40 \mu \mathrm{M})$ increased AMPA EPSCs to $239 \pm 27 \%$ of control $(n=9, p<0.001$, Fig. $5 A)$ when the external $\mathrm{Ca}^{2+}$ concentration was $2.5 \mathrm{~mm}$. Under these conditions, application of CCK failed to further increase AMPA EPSCs (Fig. 5A). To exclude the possibility that $\mathrm{Ca}^{2+}$ influx produced by the inhibition of $\mathrm{K}^{+}$channels might have saturated the release machinery and overwhelmed the effects of CCK, we reduced the external $\mathrm{Ca}^{2+}$ concentration from $2.5 \mathrm{mM}$ to $0.5 \mathrm{mM}$ to limit $\mathrm{Ca}^{2+}$ influx in the presence of 4-AP (Fig. 5B). AMPA EPSCs recorded in the presence of 4-AP with $0.5 \mathrm{mM} \mathrm{Ca}^{2+}$ were reduced almost to the initial level recorded in the absence of 4-AP with 2.5 $\mathrm{mM} \mathrm{Ca}^{2+}$ (Fig. 5B) suggesting that the release machinery is unlikely to be saturated in this condition. However, application of CCK failed to increase AMPA EPSCs in the presence of 4-AP with $0.5 \mathrm{mM} \mathrm{Ca}^{2+}$ (106 $\pm 14 \%$ of control, $n=11, p=0.7$, Fig. $\left.5 B\right)$ whereas CCK still increased AMPA EPSCs to $173 \pm 13 \%$ of control $(n=5, p=0.005)$ in the extracellular solution containing 0.5 $\mathrm{mM} \mathrm{Ca}^{2+}$ without 4 -AP (Fig. $5 \mathrm{C}$ ) suggesting that the binding of CCK to CCK-2 receptors is not affected by lower extracellular $\mathrm{Ca}^{2+}$, consistent with previous results (Bondy et al., 1989). Together, these data indicate that the function of $\mathrm{K}^{+}$channels is required for the effects of CCK.

To further examine the involvement of $\mathrm{K}^{+}$channels, we directly recorded from the identified stellate neurons. CCK did not change the resting membrane potential (control: $-60.1 \pm 0.8$ $\mathrm{mV}$, CCK: $-59.8 \pm 1.6 \mathrm{mV}, n=7, p=0.76$ ). We then recorded the voltage-dependent $\mathrm{K}^{+}$channel currents by depolarization from the holding potential of $-60 \mathrm{mV}$ (resting membrane potential) to $+60 \mathrm{mV}$ at an interval of $10 \mathrm{mV}$. The extracellular solution contained TTX $(0.5 \mu \mathrm{M})$ to block $\mathrm{Na}^{+}$channels and $\mathrm{CdCl}_{2}(100 \mu \mathrm{M})$ to block $\mathrm{Ca}^{2+}$ channels. Under these conditions, only $I_{\mathrm{K}}$ was recorded (Fig. 5D). Application of CCK $(0.3 \mu \mathrm{M})$ for $15 \mathrm{~min}$ significantly inhibited $I_{\mathrm{K}}(53 \pm 9 \%$ of control, $n=5, p=0.003$, Fig. $5 D, E)$ whereas application of the vehicle $\left(0.004 \% \mathrm{NH}_{4} \mathrm{OH}\right)$ in the extracellular solution did not significantly alter $I_{\mathrm{K}}(n=5$, $p=0.94$, Fig. $5 E$ ). To test whether CCK and 4-AP interact with the same type of $\mathrm{K}^{+}$channels, we examined the effects of CCK in the presence of 4-AP. Application of 4-AP (40 $\mu \mathrm{M})$ significantly inhibited $I_{\mathrm{K}}(56 \pm 6 \%$ of control, $n=10, p=0.001)$ and blocked the effect of CCK ( $99 \pm 3 \%$ of control, $n=10, p=0.4$, Fig. $5 F)$ suggesting that 4-AP and CCK interact with the same type of $\mathrm{K}^{+}$ channels.

\section{Signal transduction mechanisms underlying CCK-mediated increases in glutamate release}

We then examined the role of PLC pathway in CCK-mediated increases in glutamate release. Initially, we used U73122, a PLC inhibitor. Slices were pretreated with U73122 $(10 \mu \mathrm{M})$ and the extracellular solution contained the same concentration of U73122. Under these conditions, application of CCK failed to significantly increase AMPA EPSCs (Fig. 6A) whereas application of U73343 $(10 \mu \mathrm{M})$, the inactive analog of U733122, did not block CCK-mediated increases in AMPA EPSCs (Fig. 6A) suggesting that PLC activity is required. To further confirm the involvement of PLC, we used PLC knock-out mice (Kim et al., 1997; Deng and Lei, 2007; Lei et al., 2007). Among the 4 isoforms of PLC $\beta$, PLC $\beta 1$ is expressed in the hippocampus (Watanabe et al., 1998). However, CCK failed to significantly increase AMPA 
A

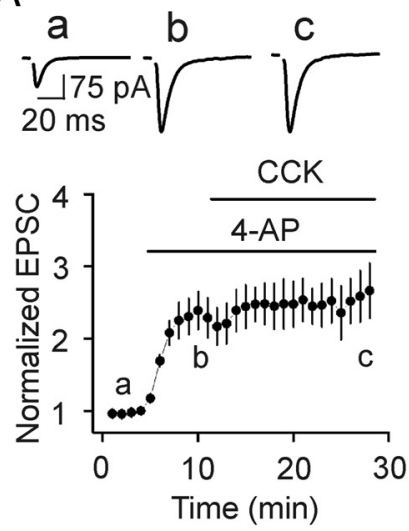

C

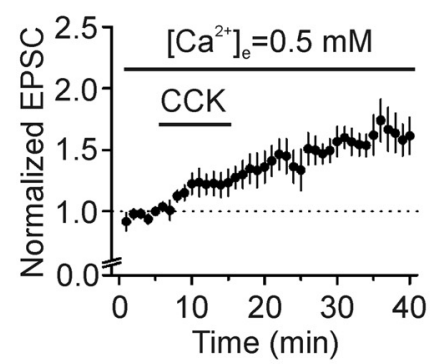

E

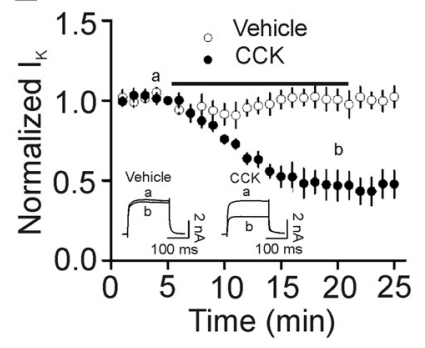

B
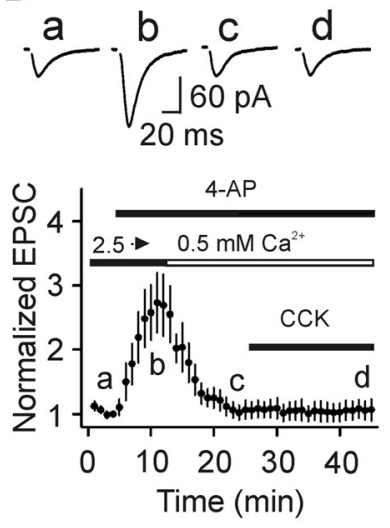

D

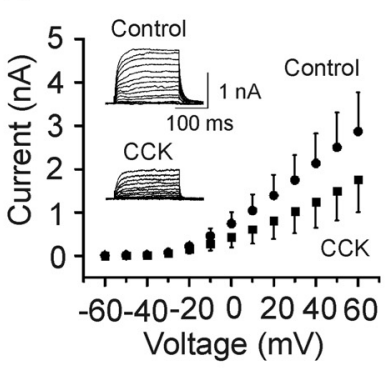

F

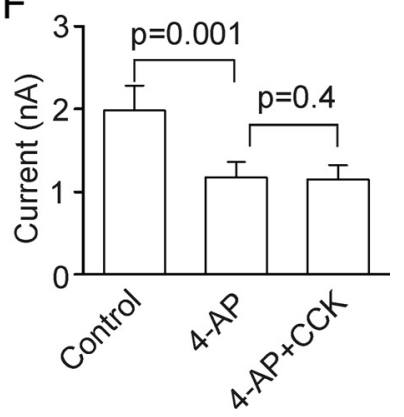

Figure 5. CCK increases glutamate release via inhibition of $\mathrm{K}^{+}$channels. $A$, Application of 4-AP $(40 \mu \mathrm{M})$ significantly increased AMPA EPSCs and blocked CCK-induced increases in AMPA EPSCs in the presence of $2.5 \mathrm{~mm} \mathrm{Ca}^{2+}(n=9)$. Top shows the current traces averaged from 10 AMPA EPSCs as indicated in the figure. $\boldsymbol{B}$, CCK failed to significantly increase AMPA EPSC $s$ when the $\mathrm{Ca}^{2+}$ concentration of extracellular solution was switched from $2.5 \mathrm{~mm}$ to $0.5 \mathrm{~mm}$ in the presence of 4-AP ( $40 \mu \mathrm{m}, n=8)$. C, CCK still increased AMPA EPSCs in the extracellular solution containing $0.5 \mathrm{~mm} \mathrm{Ca}^{2+}(n=5)$. D, CCK significantly inhibited $I_{\mathrm{K}}$ recorded from stellate neurons $(n=5)$. Insets are $I_{K}$ recorded from a stellate neuron before and during the application of CCK $(0.3 \mu \mathrm{m})$. Steady currents within $10 \mathrm{~ms}$ before the end of the depolarization pulse were measured and used to evaluate the effects of $C\left(K\right.$ on $I_{K}$. $E$, Time course of the effect of CCK or vehicle $\left(0.004 \% \mathrm{NH}_{4} \mathrm{OH}\right)$ on $I_{\mathrm{K}}$ recorded by depolarization from $-60 \mathrm{mV}$ to $+40 \mathrm{mV}$ every $30 \mathrm{~s}$. Inset shows the currents recorded before $(\boldsymbol{a})$ and during $(\boldsymbol{b})$ the application of CCK or vehicle at the time points indicated in the figure. $\boldsymbol{F}$, Summarized data showing that application of 4-AP $(40 \mu \mathrm{M})$ inhibited $I_{\mathrm{K}}$ and blocked CCK-mediated inhibition of $I_{\mathrm{K}}(n=10)$.

EPSCs recorded from the PLC $\beta 1 \mathrm{KO}$ mice $(102 \pm 4 \%$ of control, $n=13$ cells in slices cut from 4 mice, $p=0.66)$ whereas CCK still increased AMPA EPSCs in wild-type mice (156 $\pm 7 \%$ of control, $n=9$ cells in slices cut from 3 mice, $p<0.001$, Fig. $6 B$ ). Together, these results indicate that PLC $\beta 1$ is required for CCK-induced increases in glutamate release.

Activation of PLC leads to an increase in intracellular $\mathrm{Ca}^{2+}$ release and activation of $\mathrm{PKC}$. We also examined the roles of intracellular $\mathrm{Ca}^{2+}$ release and PKC in CCK-mediated increases in glutamate release. We first measured CCK-induced change in intracellular $\mathrm{Ca}^{2+}$ concentration in cultured hippocampal neu-

rons. Application of CCK significantly increased intracellular $\mathrm{Ca}^{2+}$ concentration (control: $29.9 \pm 7.4 \mathrm{nM}$, CCK: $461.6 \pm 87.7$ $\mathrm{nM}, n=10, p<0.001$, Fig. $6 C$ ) indicating that CCK induces intracellular $\mathrm{Ca}^{2+}$ release. We then tested the roles of intracellular $\mathrm{Ca}^{2+}$ release in CCK-mediated increases in glutamate release. Application of 2-aminoethoxydiphenyl borate (2-APB, $50 \mu \mathrm{M}$ ), an $\mathrm{IP}_{3}$ receptor antagonist, did not alter AMPA EPSCs (97 $\pm 5 \%$ of control, $n=10, p=0.37$ ), but significantly reduced CCKmediated increases in AMPA EPSCs $(121 \pm 3 \%$ of control, $n=$ $10, p=0.02$, Fig. $6 D$ ). These results suggest that intracellular $\mathrm{Ca}^{2+}$ release via $\mathrm{IP}_{3}$ receptors is partially responsible for CCKmediated increases in glutamate release. We then examined the roles of PKC by using two PKC inhibitors, GF109203X (0.5 $\mu \mathrm{M})$ and $\operatorname{Ro} 318220(0.5 \mu \mathrm{M})$. Bath application of either of these inhibitors completely blocked CCK-induced increases in AMPA EPSCs demonstrating that the activity of PKC is fully required (Fig. 6D). Together, these data suggest that the conventional, $\mathrm{Ca}^{2+}$-dependent PKCs are involved in CCK-mediated increases in glutamate release. Consistent with our results, activation of $\mathrm{PKC}$ increases glutamate release at PP-GC synapses (Chen and Roper, 2003).

The conventional PKCs include PKC $\alpha, \mathrm{PKC} \beta$ and PKC $\gamma$. We next examined the roles of these PKC subtypes in CCK-mediated facilitation of glutamate release using PKC knock-out mice. Application of CCK failed to significantly increase AMPA EPSCs $(3.3 \pm 3.2 \%)$ recorded from 8 cells in slices cut from 3 PKC $\gamma$ knock-out mice (The Jackson Laboratory, $p<0.01$ vs wild-type mice, Fig. $6 E$ ), but still increased AMPA EPSCs in slices cut from wild-type $(74.6 \pm 8.1 \%, n=7$ cells in slices cut from 3 mice, $p<$ $0.001)$, PKC $\alpha(60.5 \pm 8.6 \%, n=8$ cells in slices cut from 3 mice, $p=0.26$ vs wild-type mice) or PKC $\beta(80.2 \pm 17.6 \%, n=7$ cells in slices cut from 3 mice, $p=0.78$ vs wild-type mice) knock-out mice indicating that CCK increases glutamate release via activation of PKC $\gamma$.

\section{Endogenously released CCK increases AMPA EPSCs at PP-GC synapses}

The above experiments were performed by exogenous application of CCK. We next tested the role of endogenously released CCK in modulating glutamate release at the PP-GC synapses by taking the advantage that the axons of CCK-containing interneurons form a band in the inner molecular layer of the dentate gyrus (Hefft and Jonas, 2005) where PP-GC synapse forms. We tested the hypothesis that CCK released locally increases glutamate release at PP-GC synapses. As described in the method, three electrodes (one field stimulation electrode for stimulation of perforant path, two patch-clamp recording electrodes for a granule cell and an interneuron) were used. The patch-clamp electrodes contained $0.2 \%$ biocytin for post hoc immunocytochemical detection of CCK expression in interneurons (Fig. 7D). We took the advantage that the pyramidal-shaped interneurons located at the stratum granulosum/hilus border contain CCK (Acsády et al., 2000; Morozov et al., 2006) and selectively recorded from this population of interneurons. The identity of CCK-containing interneurons was verified by post hoc immunostaining for CCK (Fig. 7D, top). Analyses were limited to those interneurons showing detectable immunoreactivity for CCK. We initially recorded the basal AMPA EPSCs at the PP-GC synapses. We depolarized the interneuron via the patch pipette from -60 to $0 \mathrm{mV}$ for 100 $\mathrm{ms}$ at a frequency of $2 \mathrm{~Hz}$ for 250 times to induce CCK release. This kind of protocol has been used successfully to induce opioid peptide release in the hypothalamus (Iremonger and Bains, 2009). After stimulation of the interneuron, recording of AMPA 
EPSCs at the PP-GC synapses was reassumed. AMPA EPSCs were increased to $125 \pm 9 \%$ of control $(n=10, p=0.02$, Fig. $7 A$ ) after interneuron depolarization. Of the 10 interneurons showing positive staining for CCK, increases in AMPA EPSCs $(>115 \%$ of control as the criterion used above) were observed in 7 cells resulting in a responsive ratio of $70 \%$. However, in the presence of YM022 $(1 \mu \mathrm{M})$, a CCK-2 receptor antagonist, depolarization of interneuron failed to significantly change AMPA EPSCs ( $99 \pm 6 \%$ of control, $n=7, p=0.89$, Fig. $7 A)$. Of the 7 interneurons showing positive staining for CCK, none of the recordings showed an increase in AMPA EPSCs resulting in a responsive ratio of $0 \%$ ( $p<0.001$ vs control in the absence of YM022). To confirm the specificity of the CCK antibody, we pretreated the CCK antibody with the corresponding blocking peptide and stained 5 slices in which interneuron stimulation evoked increases in AMPA EPSCs. However, pretreatment of the CCK antibody with the corresponding blocking peptide prevented the detection of CCK immunoreactivity in interneurons in all the 5 slices (Fig. 7D, bottom) confirming the specificity of the CCK antibody.

We performed the following experiments to test whether endogenous CCK release was $\mathrm{Ca}^{2+}$-dependent and exocytosis was involved in CCK release. We first included BAPTA (20 mM) in the intracellular solution of the electrode sealed to the interneurons and repeated the above experiment. Under this condition, stimulation of interneurons failed to increase AMPA EPSCs significantly $(90.4 \pm 6.5 \%$ of control, $n=8, p=$ 0.18 , Fig. $7 B$ ). Of the 8 interneurons showing immunoreactivity to $\mathrm{CCK}$, none of the recordings showed an increase in AMPA EPSCs resulting in a responsive ratio of $0 \%(p<0.001$ vs control). This result suggests that an increase in intracellular $\mathrm{Ca}^{2+}$ is required for endogenous CCK release. Furthermore, inclusion of botulinum toxin C (BoTC, $5 \mu \mathrm{g} / \mathrm{ml}$ ) in the intracellular solution of the electrode sealed to the interneurons to cleave syntaxin prevented the increases of AMPA EPSCs induced by stimulation of interneurons $(96.7 \pm 4.1 \%$ of control, $n=8, p=0.46$, Fig. $7 C)$. Of the 8 interneurons showing CCK-positive immunostaining, one recording demonstrated an increase (119\% of control) of AMPA EPSC amplitude resulting in a responsive ratio of $12.5 \%$ which was still significantly lower than that of the control ( $p=$ 0.01 ). This result suggests that SNARE-dependent exocytosis is required for CCK release from hippocampal interneurons.

\section{Neuronal excitability is controlled by CCK-mediated modulations of both glutamate and GABA release}

In addition to increasing glutamate release, CCK also transiently facilitates, followed by a reduction in GABA release in the dentate gyrus (Deng and Lei, 2006). Because the outcome of CCKmediated modulation of transmitter release is to modify neuronal excitability, we tested the effect of CCK on neuronal excitability by recording AP firing from the dentate granule cells.
B
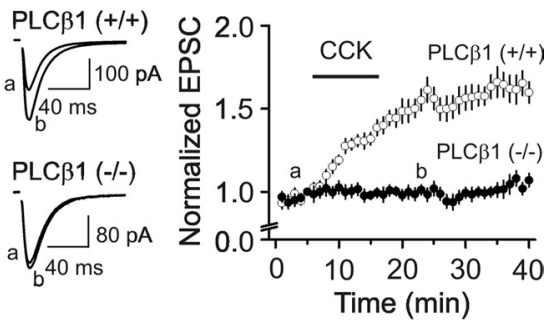

E

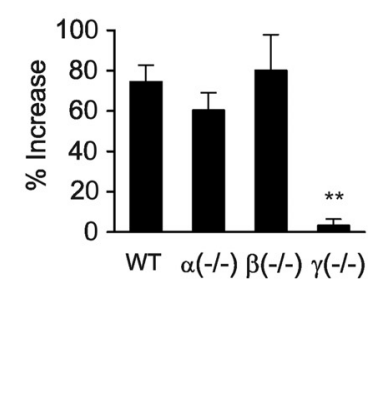

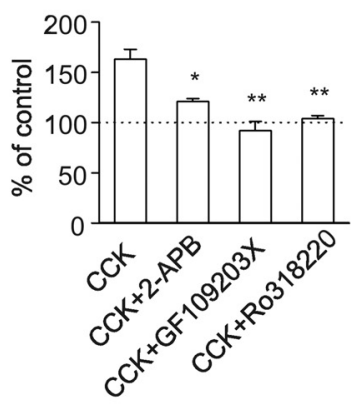

Figure 6. Signal transduction pathway underlying CCK-mediated increases in glutamate release. $A$, Pretreatment of slices with and bath application of U73122 (10 $\mu \mathrm{m})$ blocked CCK-induced increases in AMPA EPSCs $(n=8)$ whereas the same treatment of 作 significantly increased AMPA EPSCs in wild-type $[P L C \beta 1(+/+)]$ mice $(n=9$ cells in slices cut from 3 mice) but failed to change 作 significantly increased AMPA EPSCs from wild-type ( $n=7$ cells in slices cut from 3 mice), PKC $\alpha$ ( $n=8$ cells in slices cut from 3 mice) and PKC $\beta$ ( $n=7$ cells in slices cut from 3 mice) knock-out mice.

Suprathreshold positive current was continuously injected to induce AP firing at a frequency of $0.5-1 \mathrm{~Hz}$. However, granule cells could not sustain stable AP firing in the conventional whole-cell configuration. The frequency of APs was gradually reduced and eventually disappeared in $\sim 10 \mathrm{~min}$. We therefore used perforated-patch recording. In this recording configuration, the firing frequency of APs was stable and lasted for at least $50 \mathrm{~min}$ ( $109 \pm 9 \%$ of control, $n=5, p=0.49$, data not shown). We then assayed the effect of CCK on AP firing in four distinct conditions. First, experiments were performed in the normal extracellular solution to render both glutamatergic and GABAergic transmission functional. Because the maximal effect of CCK-induced facilitation of GABAergic transmission occurs in $\sim 3-5$ min after the beginning of application of CCK (Deng and Lei, 2006), we paid specific attention to the action of CCK in this period (early phase). Bath application of CCK $(0.3 \mu \mathrm{M})$ failed to alter the AP firing frequency significantly at the early phase $(91 \pm 10 \%$ of control, $n=12, p=0.39$, Fig. $8 A_{1}, A_{2}$ ) but significantly increased that recorded at the $30^{\text {th }}$ min after the beginning of its application (late phase, $192 \pm 19 \%$ of control, $n=12, p<0.001$, Fig. $\left.8 A_{1}, A_{2}\right)$. This result suggests that CCK-induced initial transient facilitation of GABA release is overwhelmed by its effect on glutamatergic transmission. Second, we tested the contribution of CCK-induced increases in glutamate release by recording APs in the extracellular solution supplemented with bicuculline $(20 \mu \mathrm{M})$ to block $\mathrm{GABA}_{\mathrm{A}}$ and CGP55845 $(5 \mu \mathrm{M})$ to block $\mathrm{GABA}_{\mathrm{B}}$ receptors. Under these circumstances, application of CCK signifi- 
A

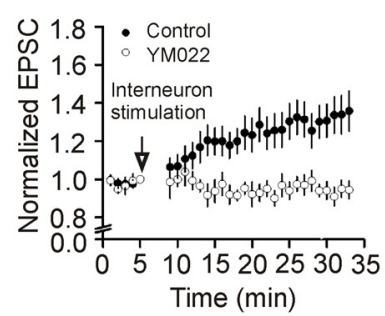

B

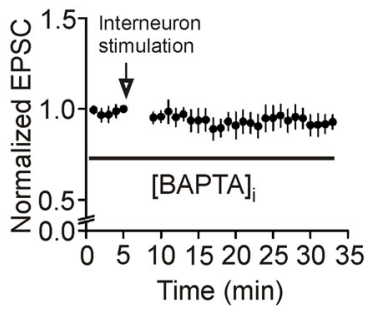

C

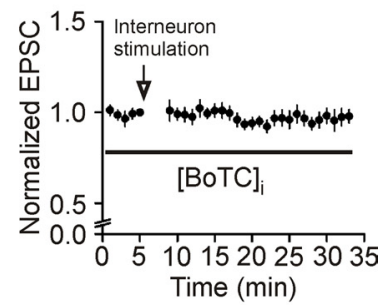

D

Biocytin

CCK

Merged

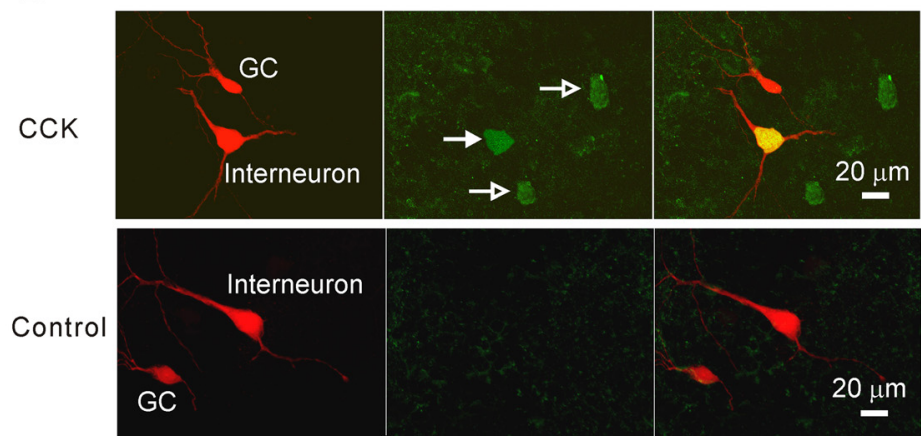

Figure 7. Endogenously released CCK increases glutamate release at PP-GC synapses. A, An electrode filled with the extracellular solution was first placed in the molecular layer of the dentate gyrus for stimulation of perforant path. Two patch-clamp electrodes filled with intracellular solution containing $0.2 \%$ biocytin were sealed to a dentate granule cell and a pyramidal-like interneuron in the border of granular layer and the hilus, respectively. Depolarizing stimulation of interneurons generated increases in AMPA EPSCs recorded from granule cells evoked by stimulation of perforant path $(n=10)$. The same experiment was performed in the presence CCK-2 receptor inhibitor, YM022 $(1 \mu \mathrm{m}, n=7)$. Note that interneuron stimulation in the presence of YM022 did not lead to an increase in AMPA EPSCS. B, C, The same experiments were performed except that the intracellular solution of the electrode sealed to the interneurons contained $20 \mathrm{~mm}$ BAPTA (B) or botulinum toxin C (BoTC, $5 \mu \mathrm{g} / \mathrm{ml})(\boldsymbol{C})$. D , The recorded dentate gyrus granule cells $(\mathrm{GC})$ and pyramidal-like interneurons located at the border of granular layer and hilus filled with biocytin were stained with Texas red-conjugated streptavidin (in red). Top, The expression of CCK in the interneurons (arrows) was detected by goat anti-CCK primary antibody and anti-goat lgG-FITC secondary antibody (in green). The merged image shows the recorded interneuron expressing CCK (in yellow). Bottom, No CCK immunoreactivity was detected when the primary CCK antibody was preabsorbed with a CCK blocking peptide in slices from which interneuron stimulation evoked an increase in AMPA EPSCS recorded at the PP-GC synapses confirming the specificity of CCK antibody.

cantly increased the firing frequency recorded at both early ( $129 \pm 9 \%$ of control, $n=10, p=0.018$, Fig. $8 B_{1}, B_{2}$ ) and late $\left(209 \pm 40 \%\right.$ of control, $n=10, p=0.022$, Fig. $\left.8 B_{1}, B_{2}\right)$ phase. Third, we assessed the effect of CCK-mediated modulation of GABAergic transmission on neuronal excitability by recording AP firing in the extracellular solution containing DNQX $(20 \mu \mathrm{M})$ to block AMPA/kainate, $d l$-APV $(100 \mu \mathrm{M})$ to block NMDA and MCPG (1 mM) to block metabotropic glutamate receptors. In this condition, CCK had a transient inhibition in the early phase $\left(63 \pm 7 \%\right.$ of control, $n=11, p<0.001$, Fig. $\left.8 C_{1}, C_{2}\right)$ but a persistent enhancement of the late phase (152 $\pm 9 \%$ of control, $n=11, p<0.001$, Fig. $\left.8 C_{1}, C_{2}\right)$. This result suggests that dentate gyrus granule cells are still under considerable tonic inhibition by GABA when glutamatergic functions are blocked. To test this possibility, we recorded AP firing in the presence of glutamate receptor inhibitors (DNQX + APV + MCPG). We then applied bicuculline and CGP55845 to block GABAergic functions. Bath application of bicuculline $(20 \mu \mathrm{M})$ and CGP55845 $(5 \mu \mathrm{M})$ in the presence of glutamate receptor inhibitors (DNQX + APV + MCPG) still increased AP firing frequency to $183 \pm 12 \%$ of control ( $n=4, p=0.006$, data not shown). Finally, we recorded AP firing in the presence of inhibitors for both glutamatergic and GABAergic transmission to exclude the possibilities that CCK could directly alter the excitability of granule cells or affect the functions of other neurotransmitters. CCK did not significantly change AP firing frequency in this situation ( $3 \mathrm{~min}: 101 \pm 3 \%$ of control, $n=9, p=0.67 ; 30 \mathrm{~min}: 93 \pm 6 \%$ of control, $n=9, p=0.28$, Fig. $\left.8 D_{1}, D_{2}\right)$. These data together demonstrate that CCK-mediated modifications of glutamatergic and GABAergic transmission contribute to neuronal network activity.

\section{Discussion}

Our results indicate that CCK augments glutamate release at PP-GC, CA3-CA3 and CA3-CA1 synapses with no effects at MF-CA3 synapses. CCK increases the number of readily releasable vesicles and release probability without effects on the rate of recovery from vesicle depletion. The effects of CCK on glutamate release are mediated by inhibition of a 4-AP-sensitive $\mathrm{K}^{+}$channel and require the functions of CCK-2 receptors, PLC, intracellular $\mathrm{Ca}^{2+}$ release and PKC. We further demonstrate that CCK endogenously released from interneurons increases glutamatergic transmission in the hippocampus.

Whereas CCK has been shown to activate a cationic conductance in rat neostriatal neurons (Wu and Wang, 1996) and supraoptic nucleus neurons (Chakfe and Bourque, 2001), our results demonstrate that CCK does not facilitate glutamate release in the hippocampus by activating cationic channels because CCK failed to modulate mEPSCs recorded from dentate granule cells and CCK had no effects on the resting membrane potentials recorded from stellate neurons in the entorhinal cortex. Our results also demonstrate that CCK does not increase glutamate release by direct interaction with and facilitation of presynaptic $\mathrm{Ca}^{2+}$ channels because application of the selective P/Q- and N-type $\mathrm{Ca}^{2+}$ channel blockers did not block CCK-induced increases in AMPA EPSCs and application of CCK failed to alter $\mathrm{Ca}^{2+}$ channel currents recorded from stellate neurons, the cell body of the perforant pathway. Actually, CCK slightly inhibits $\mathrm{Ca}^{2+}$ channels in CA1 pyramidal neurons (Shinohara and Kawasaki, 1997). Our results support the scenario that CCK inhibits $I_{\mathrm{K}}$ resulting in increases in presynaptic $\mathrm{Ca}^{2+}$ influx via voltage-gated $\mathrm{Ca}^{2+}$ channels to facilitate glutamate release in the hippocampus because application of 4-AP at micromolar concentration blocked CCKinduced increases in AMPA EPSCs and application of CCK inhibited $I_{\mathrm{K}}$ recorded from stellate neurons in the entorhinal cortex. In agreement with our results, CCK has been shown to inhibit other $\mathrm{K}^{+}$channels in a variety of neurons (Branchereau et al., 1993; Cox et al., 1995; Miller et al., 1997; Deng and Lei, 2006; Yang et al., 2007; Chung et al., 2009). Furthermore, CCK-induced increases in glutamate release gauged by measuring glutamate concentration in the perfusate of hippocampal slices (Migaud et al., 1994) and in purified rat hippocampal synaptosomes (Breukel et al., 1997) are $\mathrm{Ca}^{2+}$-dependent. CCKinduced augmentation of presynaptic $\mathrm{Ca}^{2+}$ concentration likely contributes to its increased effects on the number of readily releasable vesicles and release probability because both the mobili- 

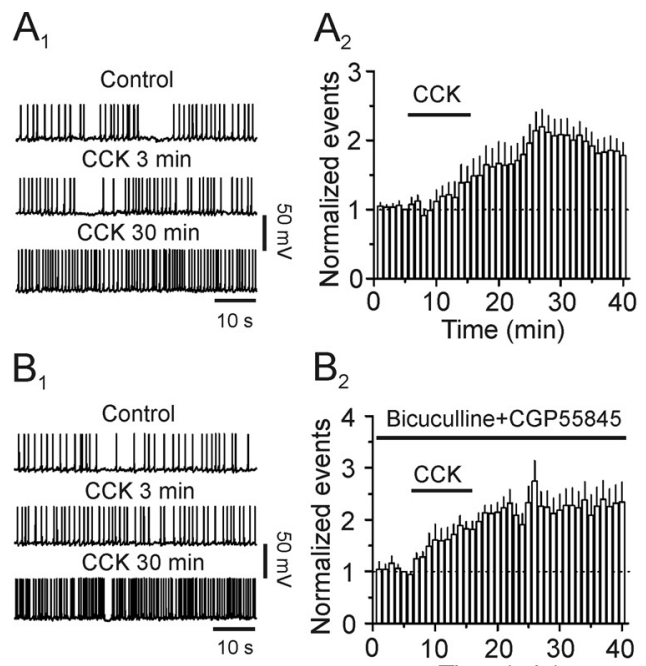

$\mathrm{B}_{2}$

$\mathrm{C}_{1}$

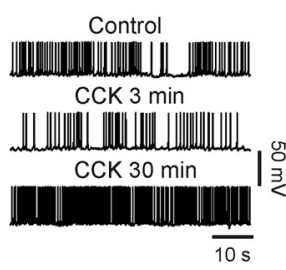

$\mathrm{D}_{1}$

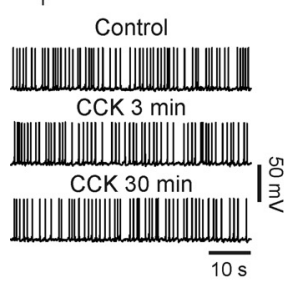

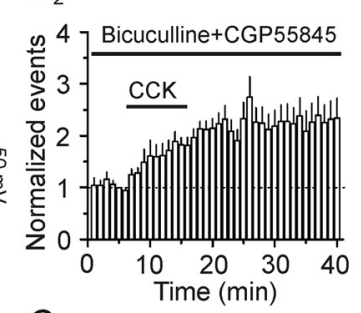

$\mathrm{C}_{2}$

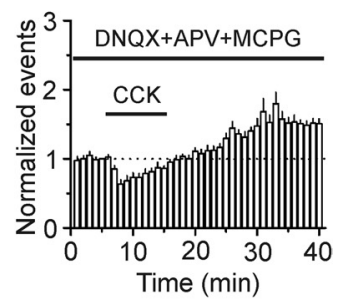

$\mathrm{D}_{2}$

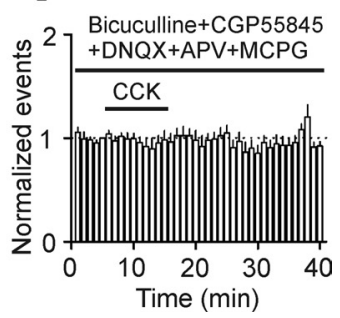

Figure 8. Contributions of $C \mathrm{CK}$-induced modulation of GABAergic and glutamatergic transmission to the excitability of dentate granule cells recorded with perforated patches. $A_{1}, A_{2}, \mathrm{CCK}$ increased the firing frequency of APs recorded in normal extracellular solution. $A_{1}, A P$ s recorded before (upper) and at the third (middle) and 30th (lower) minute after the beginning of CCK application. $A_{2}$, Summarized time course of AP firing frequency $(n=12)$. $\boldsymbol{B}_{1}, \boldsymbol{B}_{2}$, CCK facilitated the firing frequency of $A P s$ recorded in the extracellular solution supplemented with inhibitors for $\mathrm{GABA}_{A}$ (bicuculline) and $\mathrm{GABA}_{B}$ (CGP55845) receptors. $\boldsymbol{B}_{1}$, APs recorded before (upper) and at the third (middle) and 30th (lower) minute after the beginning of CCK application. $\boldsymbol{B}_{2}$, Pooled time course of AP firing frequency $(n=10) \cdot C_{1}, C_{2}, C C K$ transiently inhibited the early phase but augmented the late phase of AP firing frequency recorded in the extracellular solution containing inhibitors for glutamate receptors (DNQX, APV and MCPG). $C_{1}, A$ APs recorded before (upper) and at the third (middle) and 30th (lower) minute after the beginning of CCK application. $\boldsymbol{C}_{2}$, Pooled time course of AP firing frequency $(n=11) . \boldsymbol{D}_{1}, \boldsymbol{D}_{2}$, CCK failed to alter AP firing frequency in the presence of inhibitors for glutamatergic and GABAergic transmission $(n=9)$. Figures were arranged in the same fashion.

zation of vesicles from the reserve pool to the readily releasable pool and the release probability are $\mathrm{Ca}^{2+}$-dependent (Zucker and Regehr, 2002).

We have shown that CCK-mediated facilitation of glutamate release requires the functions of CCK-2 receptors. This conclusion is consistent with the results obtained by measuring glutamate concentration in the perfusate of hippocampal slices (Migaud et al., 1994) and in purified rat hippocampal synaptosomes (Breukel et al., 1997) after application of CCK. The following three lines of evidence indicate that presynaptic CCK-2 receptors should be responsible for CCK-induced glutamate re-

lease in the hippocampus. First, enriched CCK-binding sites have been detected in layer II of the entorhinal cortex where the cell bodies of the perforant path are located in (Köhler and ChanPalay, 1988). Second, inclusion of GDP- $\beta-S$, a G-protein inhibitor, in the recording pipettes failed to change CCK-induced increases in AMPA EPSCs whereas it blocked CCK-induced depression of $I_{\mathrm{K}}$ recorded from the stellate neurons in layer II of the entorhinal cortex. Third, Breukel et al. (1997) have shown that CCK increases glutamate release in purified hippocampal synaptosomes because in this preparation the continuity of presynaptic and postsynaptic structures should be disconnected. We further demonstrate that the down-stream targets of CCK-2 receptors, PLC, intracellular $\mathrm{Ca}^{2+}$ and PKC $\gamma$ are involved in CCK-induced increases in glutamate release. Because our results demonstrate that CCK augments glutamate release by inhibiting presynaptic $I_{\mathrm{K}}$, it is reasonable to speculate that the activated PKC $\gamma$ phosphorylates $I_{\mathrm{K}}$ or $I_{\mathrm{K}}$-associated proteins resulting in an inhibition of $I_{\mathrm{K}}$. Consistent with our results, activation of PKC has been shown to inhibit $I_{\mathrm{K}}$ in neurons cultured from rat hypothalamus and brainstem (Pan et al., 2001) and in cerebrocortical synaptosomes (Barrie et al., 1991) and $I_{\mathrm{K}}$ expressed in Xenopus oocytes (Peretz et al., 1996).

CCK has been shown to transiently increase GABA release in hippocampal CA1 region (Miller et al., 1997; Deng and Lei, 2006; Földy et al., 2007; Karson et al., 2008). However, these studies did not examine the late effect of CCK on GABAergic transmission. We have previously shown that CCK exerts bidirectional modification, with initial transient enhancement followed by a persistent depression, of GABAergic transmission onto the granule cells of the dentate gyrus (Deng and Lei, 2006). Here, we further assessed the contribution of glutamatergic and GABAergic transmission to CCK-mediated modification of the excitability of granule cells. Our results demonstrate that CCK-mediated initial transient enhancement of GABA release does not lead to a perceptible inhibition of the excitability of granule cells when both GABAergic and glutamatergic transmissions are functional. The possible reason is that the inhibition derived from CCK-induced transient augmentation of GABA release is inundated by its action on glutamate release because the initial inhibitory effect of CCK on neuronal excitability was unfolded when glutamatergic transmission was inhibited. However, these results do not deny a potential function for CCK-induced initial increase in GABAergic transmission because it is possible that this kind of modification may exert a fine-tuning on neuronal network activity. Nonetheless, CCK-induced late phase inhibition on GABAergic transmission is in line with its effect on glutamatergic transmission. The concerted actions of CCK on GABAergic and glutamatergic transmissions likely lead to an increase in neuronal excitability. CCK has long been known to exert anxiogenic effects in both animal models and humans (Rehfeld, 2000) and the generation of anxiety can be due to a reduction in GABAergic (Rupprecht et al., 2006; Whiting, 2006) and/or an increase of glutamatergic (Bergink et al., 2004) function. Our results are agreeable with this scenario and may serve as the cellular and molecular mechanisms to explain the anxiogenic effects of CCK. In addition, CCK has also been implicated in modulating other important brain functions including satiety, analgesia, learning and memory processes (Sebret et al., 1999; Rehfeld, 2000; Beinfeld, 2001), which are closely related to both glutamate and GABA. Our results therefore provide a basis to explain the roles of CCK in these physiological functions as well. 


\section{References}

Acsády L, Katona I, Martínez-Guijarro FJ, Buzsáki G, Freund TF (2000) Unusual target selectivity of perisomatic inhibitory cells in the hilar region of the rat hippocampus. J Neurosci 20:6907-6919.

Barrie AP, Nicholls DG, Sanchez-Prieto J, Sihra TS (1991) An ion channel locus for the protein kinase $\mathrm{C}$ potentiation of transmitter glutamate release from guinea pig cerebrocortical synaptosomes. J Neurochem 57:1398-1404.

Beinfeld MC (2001) An introduction to neuronal cholecystokinin. Peptides 22:1197-1200.

Bergink V, van Megen HJ, Westenberg HG (2004) Glutamate and anxiety. Eur Neuropsychopharmacol 14:175-183.

Boden PR, Hill RG (1988) Effects of cholecystokinin and pentagastrin on rat hippocampal neurones maintained in vitro. Neuropeptides 12:95-103.

Böhme GA, Stutzmann JM, Blanchard JC (1988) Excitatory effects of cholecystokinin in rat hippocampus: pharmacological response compatible with 'central'- or B-type CCK receptors. Brain Res 451:309-318.

Bondy CA, Jensen RT, Brady LS, Gainer H (1989) Cholecystokinin evokes secretion of oxytocin and vasopressin from rat neural lobe independent of external calcium. Proc Natl Acad Sci U S A 86:5198-5201.

Branchereau P, Champagnat J, Denavit-Saubié M (1993) Cholecystokiningated currents in neurons of the rat solitary complex in vitro. J Neurophysiol 70:2584-2595.

Breukel AI, Lopes da Silva FH, Ghijsen WE (1997) Cholecystokinin (CCK-8) modulates vesicular release of excitatory amino acids in rat hippocampal nerve endings. Neurosci Lett 234:67-70.

Brooks PA, Kelly JS (1985) Cholecystokinin as a potent excitant of neurons of the dentate gyrus of rats. Ann N Y Acad Sci 448:361-374.

Chakfe Y, Bourque CW (2001) Peptidergic excitation of supraoptic nucleus neurons: involvement of stretch-inactivated cation channels. Exp Neurol 171:210-218.

Chen HX, Roper SN (2003) PKA and PKC enhance excitatory synaptic transmission in human dentate gyrus. J Neurophysiol 89:2482-2488.

Chung L, Moore SD, Cox CL (2009) Cholecystokinin action on layer 6b neurons in somatosensory cortex. Brain Res 1282:10-19.

Coetzee WA, Amarillo Y, Chiu J, Chow A, Lau D, McCormack T, Moreno H, Nadal MS, Ozaita A, Pountney D, Saganich M, Vega-Saenz de Miera E, Rudy B (1999) Molecular diversity of K+ channels. Ann N Y Acad Sci 868:233-285.

Cox CL, Huguenard JR, Prince DA (1995) Cholecystokinin depolarizes rat thalamic reticular neurons by suppressing a $\mathrm{K}+$ conductance. J Neurophysiol 74:990-1000.

de Tullio P, Delarge J, Pirotte B (1999) Recent advances in the chemistry of cholecystokinin receptor ligands (agonists and antagonists). Curr Med Chem 6:433-455.

Deng PY, Lei S (2006) Bidirectional modulation of GABAergic transmission by cholecystokinin in hippocampal dentate gyrus granule cells of juvenile rats. J Physiol 572:425-442.

Deng PY, Lei S (2007) Long-term depression in identified stellate neurons of juvenile rat entorhinal cortex. J Neurophysiol 97:727-737.

Deng PY, Porter JE, Shin HS, Lei S (2006) Thyrotropin-releasing hormone increases GABA release in rat hippocampus. J Physiol 577:497-511.

Deng PY, Poudel SK, Rojanathammanee L, Porter JE, Lei S (2007) Serotonin inhibits neuronal excitability by activating two-pore domain $\mathrm{k}+$ channels in the entorhinal cortex. Mol Pharmacol 72:208-218.

Deng PY, Xiao Z, Yang C, Rojanathammanee L, Grisanti L, Watt J, Geiger JD, Liu R, Porter JE, Lei S (2009) GABA(B) receptor activation inhibits neuronal excitability and spatial learning in the entorhinal cortex by activating TREK-2 K+ channels. Neuron 63:230-243.

Dodd J, Kelly JS (1981) The actions of cholecystokinin and related peptides on pyramidal neurones of the mammalian hippocampus. Brain Res 205:337-350.

Földy C, Lee SY, Szabadics J, Neu A, Soltesz I (2007) Cell type-specific gating of perisomatic inhibition by cholecystokinin. Nat Neurosci 10:11281130.

Goda Y, Stevens CF (1994) Two components of transmitter release at a central synapse. Proc Natl Acad Sci U S A 91:12942-12946.

Greenwood RS, Godar SE, Reaves TA Jr, Hayward JN (1981) Cholecystokinin in hippocampal pathways. J Comp Neurol 203:335-350.

Gronier B, Debonnel G (1995) CCKB receptors mediate CCK-8S-induced activation of dorsal hippocampus CA3 pyramidal neurons: an in vivo electrophysiological study in the rat. Synapse 21:158-168.
Hefft S, Jonas P (2005) Asynchronous GABA release generates long-lasting inhibition at a hippocampal interneuron-principal neuron synapse. Nat Neurosci 8:1319-1328.

Hill DR, Campbell NJ, Shaw TM, Woodruff GN (1987) Autoradiographic localization and biochemical characterization of peripheral type CCK receptors in rat CNS using highly selective nonpeptide CCK antagonists. J Neurosci 7:2967-2976.

Hill DR, Shaw TM, Graham W, Woodruff GN (1990) Autoradiographical detection of cholecystokinin-A receptors in primate brain using 125IBolton Hunter CCK-8 and ${ }^{3}$ H-MK-329. J Neurosci 10:1070-1081.

Iremonger KJ, Bains JS (2009) Retrograde opioid signaling regulates glutamatergic transmission in the hypothalamus. J Neurosci 29:7349-7358.

Jaffe DB, Aitken PG, Nadler JV (1987) The effects of cholecystokinin and cholecystokinin antagonists on synaptic function in the CA1 region of the rat hippocampal slice. Brain Res 415:197-203.

Karson MA, Whittington KC, Alger BE (2008) Cholecystokinin inhibits endocannabinoid-sensitive hippocampal IPSPs and stimulates others. Neuropharmacology 54:117-128.

Kim D, Jun KS, Lee SB, Kang NG, Min DS, Kim YH, Ryu SH, Suh PG, Shin HS (1997) Phospholipase C isozymes selectively couple to specific neurotransmitter receptors. Nature 389:290-293.

Köhler C, Chan-Palay V (1988) Cholecystokinin-octapeptide (CCK-8) receptors in the hippocampal region: a comparative in vitro autoradiographic study in the rat, monkey and the postmortem human brain. Neurosci Lett 90:51-56.

Kritzer MF, Innis RB, Goldman-Rakic PS (1988) Regional distribution of cholecystokinin receptors in macaque medial temporal lobe determined by in vitro receptor autoradiography. J Comp Neurol 276:219-230.

Lei S, Deng PY, Porter JE, Shin HS (2007) Adrenergic facilitation of GABAergic transmission in rat entorhinal cortex. J Neurophysiol 98: $2868-2877$.

Leitges M, Schmedt C, Guinamard R, Davoust J, Schaal S, Stabel S, Tarakhovsky A (1996) Immunodeficiency in protein kinase cbetadeficient mice. Science 273:788-791.

Leitges M, Plomann M, Standaert ML, Bandyopadhyay G, Sajan MP, Kanoh Y, Farese RV (2002) Knockout of PKC alpha enhances insulin signaling through PI3K. Mol Endocrinol 16:847-858.

Migaud M, Roques BP, Durieux C (1994) Effects of cholecystokinin octapeptide and BC 264, a potent and selective CCK-B agonist on aspartate and glutamate release from rat hippocampal slices. Neuropharmacology 33:737-743.

Miller KK, Hoffer A, Svoboda KR, Lupica CR (1997) Cholecystokinin increases GABA release by inhibiting a resting $\mathrm{K}+$ conductance in hippocampal interneurons. J Neurosci 17:4994-5003.

Monaghan MM, Trimmer JS, Rhodes KJ (2001) Experimental localization of Kv1 family voltage-gated $\mathrm{K}+$ channel alpha and beta subunits in rat hippocampal formation. J Neurosci 21:5973-5983.

Moran TH, Robinson PH, Goldrich MS, McHugh PR (1986) Two brain cholecystokinin receptors: implications for behavioral actions. Brain Res 362:175-179.

Morozov YM, Ayoub AE, Rakic P (2006) Translocation of synaptically connected interneurons across the dentate gyrus of the early postnatal rat hippocampus. J Neurosci 26:5017-5027.

Nagata A, Ito M, Iwata N, Kuno J, Takano H, Minowa O, Chihara K, Matsui T, Noda T (1996) G protein-coupled cholecystokinin-B/gastrin receptors are responsible for physiological cell growth of the stomach mucosa in vivo. Proc Natl Acad Sci U S A 93:11825-11830.

Nishida A, Miyata K, Tsutsumi R, Yuki H, Akuzawa S, Kobayashi A, Kamato T, Ito H, Yamano M, Katuyama Y, Satoh M, Ohta M, Honda K (1994) Pharmacological profile of $(R)$-1-[2,3-dihydro-1-(2'-methylphenacyl)2-oxo-5-phenyl-1H-1,4-benzodiazepin-3-yl]-3-(3-methylphenyl)urea (YM022), a new potent and selective gastrin/cholecystokinin-B receptor antagonist, in vitro and in vivo. J Pharmacol Exp Ther 269:725-731.

Nunzi MG, Gorio A, Milan F, Freund TF, Somogyi P, Smith AD (1985) Cholecystokinin-immunoreactive cells form symmetrical synaptic contacts with pyramidal and nonpyramidal neurons in the hippocampus. J Comp Neurol 237:485-505.

Oliet SH, Malenka RC, Nicoll RA (1996) Bidirectional control of quantal size by synaptic activity in the hippocampus. Science 271:1294-1297.

Pan SJ, Zhu M, Raizada MK, Sumners C, Gelband CH (2001) ANG IImediated inhibition of neuronal delayed rectifier $\mathrm{K}+$ current: role of protein kinase C-alpha. Am J Physiol Cell Physiol 281:C17-23. 
Peretz T, Levin G, Moran O, Thornhill WB, Chikvashvili D, Lotan I (1996) Modulation by protein kinase $\mathrm{C}$ activation of rat brain delayed-rectifier $\mathrm{K}+$ channel expressed in Xenopus oocytes. FEBS Lett 381:71-76.

Qian J, Noebels JL (2001) Presynaptic $\mathrm{Ca}^{2+}$ channels and neurotransmitter release at the terminal of a mouse cortical neuron. J Neurosci 21:37213728.

Rehfeld JF (2000) Cholecystokinin and panic disorder-three unsettled questions. Regul Pept 93:79-83.

Rehfeld JF, Hansen HF, Marley PD, Stengaard-Pedersen K (1985) Molecular forms of cholecystokinin in the brain and the relationship to neuronal gastrins. Ann N Y Acad Sci 448:11-23.

Rupprecht R, Eser D, Zwanzger P, Möller HJ (2006) GABAA receptors as targets for novel anxiolytic drugs. World J Biol Psychiatry 7:231-237.

Schneggenburger R, Meyer AC, Neher E (1999) Released fraction and total size of a pool of immediately available transmitter quanta at a calyx synapse. Neuron 23:399-409.

Sebret A, Léna I, Crété D, Matsui T, Roques BP, Daugé V (1999) Rat hippocampal neurons are critically involved in physiological improvement of memory processes induced by cholecystokinin-B receptor stimulation. J Neurosci 19:7230-7237.

Shinohara S, Kawasaki K (1997) Electrophysiological changes in rat hippocampal pyramidal neurons produced by cholecystokinin octapeptide. Neuroscience 78:1005-1016.

Sinton CM (1988) Cholecystokinin modulates neurotransmission through the dentate gyrus. Neurosci Lett 95:341-346.

Somogyi P, Hodgson AJ, Smith AD, Nunzi MG, Gorio A, Wu JY (1984) Different populations of GABAergic neurons in the visual cortex and hippocampus of cat contain somatostatin- or cholecystokinin-immunoreactive material. J Neurosci 4:2590-2603.

Su SF, Amidon GL, Lee HJ (2002) Intestinal metabolism and absorption of cholecystokinin analogs in rats. Biochem Biophys Res Commun 292:632-638.
Taschenberger H, Leão RM, Rowland KC, Spirou GA, von Gersdorff H (2002) Optimizing synaptic architecture and efficiency for highfrequency transmission. Neuron 36:1127-1143.

Van Dijk A, Richards JG, Trzeciak A, Gillessen D, Möhler H (1984) Cholecystokinin receptors: biochemical demonstration and autoradiographical localization in rat brain and pancreas using $\left[{ }^{3} \mathrm{H}\right]$ cholecystokinin 8 as radioligand. J Neurosci 4:1021-1033.

Wank SA (1995) Cholecystokinin receptors. Am J Physiol 269:G628-G646.

Watanabe M, Nakamura M, Sato K, Kano M, Simon MI, Inoue Y (1998) Patterns of expression for the mRNA corresponding to the four isoforms of phospholipase Cbeta in mouse brain. Eur J Neurosci 10:2016-2025.

Whiting PJ (2006) GABA-A receptors: a viable target for novel anxiolytics? Curr Opin Pharmacol 6:24-29.

Wu T, Wang HL (1996) The excitatory effect of cholecystokinin on rat neostriatal neurons: ionic and molecular mechanisms. Eur J Pharmaco 307:125-132.

Xiao Z, Deng PY, Rojanathammanee L, Yang C, Grisanti L, Permpoonputtana K, Weinshenker D, Doze VA, Porter JE, Lei S (2009) Noradrenergic depression of neuronal excitability in the entorhinal cortex via activation of TREK-2 K+ channels. J Biol Chem 284:10980-10991.

Yang YM, Chung JM, Rhim H (2007) Cholecystokinin-8S-induced intracellular calcium signaling in acutely isolated periaqueductal gray neurons of the rat. Biol Pharm Bull 30:297-302.

You ZB, Herrera-Marschitz M, Brodin E, Meana JJ, Morino P, Hökfelt T, Silveira R, Goiny M, Ungerstedt U (1994) On the origin of striatal cholecystokinin release: studies with in vivo microdialysis. J Neurochem 62:76-85.

Yu MJ, Thrasher KJ, McCowan JR, Mason NR, Mendelsohn LG (1991) Quinazolinone cholecystokinin-B receptor ligands. J Med Chem 34:15051508.

Zucker RS, Regehr WG (2002) Short-term synaptic plasticity. Annu Rev Physiol 64:355-405. 